\title{
Trajetórias Tecnológicas como Objeto de Política de Conhecimento para a Amazônia: uma metodologia de delineamento*
}

\author{
Francisco de Assis Costa
}

Núcleo de Altos Estudos Amazônicos e Programa de Pós-Graduação

em Economia da Universidade Federal do Pará

\section{Resumo}

A relação entre o conhecimento apropriado no processo produtivo e as características atuais e possibilidades futuras de desenvolvimento de base agrária na Amazônia tem merecido uma rica reflexão entre policy makers e advisers em posiçōes relevantes no campo científico e tecnológico. Reconhece-se, cada vez mais, que, para se fazer frente às grandes tensões por que passa a região mediante a crise ecológica por trás do aquecimento global, há a necessidade de subverter a produção de ciência e tecnologia e a atitude do estado, revertendo a abordagem em relação à região, daquela atual, que a considera uma economia de fronteira baseada em produtividade espúria (Fajnzylber, 1988; Egler, 2006), para outra que a trate como uma fronteira do capital natural (Becker, 2004). Disso faria parte a formação de uma matriz de conhecimento com nexos consistentes entre conhecimento tácito das populações tradicionais e conhecimento codificado (Sá, 2006) e a integração entre o universo da produção de mercadorias e o da produção de conhecimento, de modo a garantir a formação de clusters competitivos de produtos e serviços baseados no uso sustentável dos recursos naturais (Vieira, 2006).

Utilizando as noções de paradigmas tecnológicas e de desenvolvimento dependente de trajetória (Dosi, 2006; Arthur, 1994), o artigo procura tornar claras as dificuldades de tal reviravolta: uma vez que entre uma sociedade baseada em economia de fronteira e uma sociedade que seja fronteira de capital natural, há o abismo cognitivo criado pela razão industrialista e seus padrões de relação

\footnotetext{
* Trabalho realizado com o apoio do CGEE, posto que resultou de texto escrito por sua solicitação (ver Costa, 2006). O trabalho se beneficiou extraordinariamente dos comentários de Diógenes Alves do Instituto Nacional de Pesquisas Espaciais (INPE). Foram também de extraordinária valia os comentários e recomendações de três pareceristas anônimos, aos quais agradeço enfaticamente.
} 
com a natureza, na forma de um paradigma de modernização industrial da agricultura, poderoso de muitos modos; uma vez que, também, entre instituições de acúmulo de conhecimento tácito e as de conhecimento codificado há a incongruência de suas respectivas matrizes, desde a profunda distinção nas percepções de sujeito e objeto até a visão de finalidade e sentido; uma vez que, finalmente, nos clusters e aglomerados locais residem assimetrias profundas, em que os paradigmas e padrões de relação com a natureza e a natureza dos paradigmas organizacionais consolidam práxis e atitudes profundamente distintivas - dos sujeitos da produção material entre si e entre estes e os sujeitos da formação e do controle do conhecimento.

Com resultados da aplicação de técnicas de análise fatorial e de componentes principais aplicadas a uma base especial de dados do Censo agropecuário de 1995-1996 regionalizados em nível de microrregião, o artigo delimita seis trajetórias tecnológicas na Amazônia. Nelas as diferenças são especificadas a partir da diversidade estrutural e dos tipos de agentes. Verificam-se, isso posto, a importância social, a coerência com os critérios privados dominantes, as características tecnológicas expressas nas disponibilidades de capital físico e nas relaçôes com os fundamentos naturais disponíveis, além do grau de favorecimento em relação aos mecanismos da política agrária.

Expostas as trajetórias e suas posições paradigmáticas, a capacidade respectiva de concorrência e dinâmica demonstrada nos últimos dez anos, o artigo discute opções estratégicas, indicando a necessidade de esforços institucionais objetivos para tornar mais consistentes os fundamentos das trajetórias que poderiam favorecer um desenvolvimento com maior esperança de sustentabilidade (social e ambiental).

Palavras-Chave | Amazônia; Desenvolvimento Regional; Trajetórias Tecnológicas; Desenvolvimento Rural; Instituições

Códigos JEL | O13; O18

\section{Abstract}

The relationship between the knowledge adapted in the productive process and the current characteristics and future possibilities of agrarian development of Amazon has been deserving a rich reflection by important policy makers and advisers of the institutional field of Science \& Technology in Brazil. It is more and more recognized, that to tackle in the region the great tensions resulting of the ecological crisis behind the global heating and climate change, it is necessary to subvert the production of S\&T and the attitude of the State. It means, to revert the policy approach, of that current one, which considers the region as an "economy of open frontier" based on spurious productivity (Fajnzylber, 1988; Egler, 2006), for another that treats it as a "frontier of the natural capital" (Becker, 2004). Part of that would be the formation of a knowledge matrix able to 
connect consistently the tacit knowledge of the traditional populations with the codified knowledge of the S\&T institutions (Sá, 2006). Part would be the integration between the universe of the production of goods and the one of the production of knowledge to guarantee the building up of competitive clusters of products and services based on the sustainable use of the natural resources (Vieira, 2006).

Starting from the notions of "technological paradigms and trajectories" (Dosi, 2006) and of "competing technologies and path-dependent development" (Arthur, 1994), the article try to clear the difficulties of such revision. It argues first that between a society exploring a "economy of open frontier" and a society able to make true a "frontier of the natural capital" there exist the cognitive abyss created by the capitalist-industrialist reason and its relationship patterns with the nature, in the form of a paradigm of industrial modernization of the agriculture, powerful in many manners. It stresses further that also between institutions that generate and accumulate tacit knowledge and those which generate and accumulate codified knowledge there is the incongruity of their perspectives, from the deep distinction in subject's and object's perceptions, until the vision of purpose and direction. It points out, finally, that in the cluster and agglomerates reside deep asymmetries, where the paradigms and relationship patterns with the nature and the nature of the organizational paradigms consolidate practices and deeply distinctive attitudes - both of the subjects of the material production to each other and among those and the subjects of the formation and control of the knowledge.

With results from factorial and main components statistic analysis applied to a special base of data of the Agricultural Census of 1995-1996 regionalized at micro-regional level, the article defines six technological trajectories for the Brazilian north region - the Amazon region. The differences among them were specified starting from the prevailing main characteristic of both structures and types of agents who control the establishments. They were further verified through the technological characteristics of the productive units expressed in the endowment of physical capital and in the relationships with the available natural resources. Besides the degrees with that they participated in the agricultural politics were approximated.

Exposed the trajectories and their paradigms, their respective capacity of competition and dynamics demonstrated in the last ten years, the article discusses strategic options, indicating the need of objective institutional efforts to turn more consistent the foundations of the trajectories that could favor a development with larger hope of (social and environmental) sustainability.

KEYwords I Amazônia; Regional Development; Technological Trajectories; Rural Development; Institutions

JEL-CODES | O13; O18 


\section{Introdução}

A relação entre o conhecimento, em particular o conhecimento técnico apropriado no processo produtivo, e as características atuais e possibilidades futuras de desenvolvimento de base agrária na Amazônia tem merecido uma rica reflexão entre policy makers e advisers em posições relevantes no campo científico e tecnológico que têm a região como uma de suas referências. Partindo do reconhecimento de que as dinâmicas observadas configuram um desenvolvimento baseado em produtividade espúria (Fajnzylber, 1988) “[...] que leva a uma progressiva depreciação da mão de obra local, a um esgotamento acelerado da base de recursos naturais e a uma degradação ambiental contínua dos ecossistemas" (Egler, 2006), observa-se a necessidade de uma mudança na atitude do Estado nacional, alterando sua abordagem em relação à região, daquela atual, que a considera uma economia de fronteira (Becker, 2005a), para outra que a trate como uma fronteira do capital natural (Becker, 2005b), do que faria parte uma revolução científico-tecnológica (Becker, 2007). ${ }^{1}$

Isso exigiria dois movimentos. Um que produzisse bases institucionais para a formação de uma matriz de conhecimento que mostrasse nexos consistentes entre conhecimento tácito e conhecimento codificado no que se refere ao uso da base natural da região, permitindo a interação de "[...] duas redes de inovação: i) rede de inovação institucional (instituições de pesquisa, universidades) e ii) rede de inovação tradicional (povos indígenas e diversos tipos de populações tradicionais) [...]" (Sá, 2006). Outro que estabelecesse os nexos institucionais de integração entre o universo da produção de mercadorias e o da produção de conhecimento, de modo a garantir "[...] a formação de clusters competitivos de produtos e processos baseados no uso sustentável dos nossos recursos naturais" (Vieira, 2006).

Tais posições vêm permeando as avaliações encampadas por organizaçôes de grande relevância para a região. Em documento conjunto, o Centro de Gestão e Estudos Estratégicos (CGEE), a Empresa Brasileira de Pesquisa Agropecuária (Embrapa) e o Conselho das Entidades Estaduais de Pesquisa Agropecuária (CONSEPA) sublinham que a Amazônia deve ser encarada como "[...] objeto de observação especial, devido a sua importância estratégica para a pesquisa científica agropecuária” (CGEE-MCT/

1 Essas noções estão aplicadas aqui nos significados utilizados pela geógrafa Berta Becker, para quem a "economia de fronteira" representa um padrão exportador de matérias-primas valorizadas no mercado externo, cujo crescimento, visto como linear e infinito, se faria através da incorporação de terra e produtos naturais (Becker, 2005:4.001); uma "fronteira do capital natural" seria um território onde "eldorados naturais" com grande disponibilidade de recursos vitais para a vida humana - o ar, a água, a biodiversidade - estariam sofrendo tensões que levariam ao processo de mercantilização, à transformação de bens da natureza em mercadorias (Becker, 2005:74-77). 
Embrapa/CONSEPA, 2006), sendo tal relevância definida em documento mais específico em termos das disponibilidades naturais, dos usos atuais que delas se fazem e das perspectivas que podem oferecer. Parece estabelecido o entendimento de que, destacando-se a região pela sua biodiversidade, pelas reservas de recursos naturais que abriga e pelas tensões sobre elas exercidas por legítimas aspirações de produtores agrícolas e demais segmentos populacionais nela radicados, a perspectiva estratégica que deve orientar uma requalificação da pesquisa agropecuária na região deverá ser a que prioriza a utilização do potencial de recursos humanos, culturais e naturais com base num modelo de "exploração" sustentável nas dimensões econômica, social e cultural (CGEE-MCT/Embrapa/CONSEPA, 2006:1).

\subsection{Questionamento}

As decisões orientadas por tais disposições portam riscos relevantes. É que sua efetivação implicará grandes rupturas - no que se refere às matrizes de conhecimento, no que se refere ao portfólio tecnológico disponível, no que se refere à cultura institucional dominante e, por fim, mas de modo algum menos importante, no que se refere às concepções subjetivas de mundo e devir. Entre uma sociedade baseada em economia de fronteira e uma sociedade que seja fronteira de capital natural, há o abismo cognitivo criado pela razão industrialista ${ }^{2}$ e seus padrões de relação com a natureza, na forma de um paradigma de modernização industrial da agricultura, poderoso de muitos modos. Entre instituições de acúmulo de conhecimento tácito e as de conhecimento codificado, há a incongruência de suas respectivas matrizes, desde a profunda distinção nas percepções de sujeito e objeto até a visão de finalidade e sentido. No aglomerado, por seu turno, residem assimetrias profundas, em que os paradigmas e padróes de relação com a natureza e a natureza dos paradigmas organizacionais consolidam práxis e atitudes profundamente distintivas - dos sujeitos da produção material entre si e entre esses e os sujeitos da formação e do controle do conhecimento.

Isso posto, parece claro que superar tais problemas requer mudanças igualmente importantes no quadro organizacional e nas atitudes. Será necessário, por suposto, redefinir, subverter mesmo o papel desempenhado pela institucionalidade de ciência e tecnologia na região. Não obstante, não são óbvios nem os sujeitos nem os

\footnotetext{
2 A "ciência moderna" é industrialista porque "[...] se desenvolve sob o signo da instrumentalização e apropriação da natureza; esta é vista como passível de dominação racional e técnica pelo homem" (Morel, 1979).
} 
objetos de tal subversão: Quem, na Amazônia, submetido a que razão, promoverá qual conhecimento tácito ou codificado? Quem, nessa enorme e diversa região, submetido a que razão, valorizará qual capital natural? Quem, nesse espaço onde se espera orientação ao desenvolvimento sustentável, validando que razão, liderará quem em tais movimentos? Eis as questões que nos é exigido responder - referência de fundo do esforço que adiante se fará.

\subsection{0 encaminhamento teórico 1: diversidade de agentes e estruturas e percepção complexa de suas relações}

As questōes acima exigem capacidade teórica de tratamento da diversidade de sujeitos e fundamentos. Em relação a isso, a economia vive um momento particularmente fértil, após décadas de prevalência de percepções baseadas em estruturas e agentespadrão. Uma convergência entre as tradições schumpeteriana e keynesiana (Possas et al. 2001), dessas com aspectos importantes da tradição marxista, através de Kalecki (Possas, 1999) e da Escola da Regulação Francesa (Boyer, 1988) e com as abordagens da Nova Economia Institucional e do desenvolvimento endógeno (Castro, 2004), vem produzindo perspectivas inteiramente novas na observação da dinâmica das relaçôes ação/agente-estrutura/agência, esse antigo dilema metodológico das ciências da sociedade. Com isso, criou-se a possibilidade de analisar o desenvolvimento como processo dependente de trajetória em contextos marcados espacial e historicamente por diversidade estrutural e tecnologias concorrentes.

Desse esforço tem emergido programas de pesquisa orientados pela hipótese de que a conformação de uma dada realidade social tem um momento fundamental na combinação dos meios disponíveis para a produção e para a gestão da produção em tecnologias geradas e difundidas em processos, nos quais agentes heterogêneos, caracterizados por uma racionalidade limitada, no sentido (forte) de Simon (1983), tomam decisões em ambientes de incerteza, no sentido (radical) de Keynes (1970), marcados (1) por dinâmicas competitivas, cujo estado dominante é o do desequilíbrio entre as forças decisivas e (2) a isso associado por uma considerável complexidade e diversidade institucional (Nelson \& Winter, 1982). Em tal contexto, decisōes sobre mudança e inovação associam-se a processos de aprendizado que "[...] podem ser vistos como competição dinâmica entre diferentes hipóteses ou crenças ou ações" (Arthur, 1994:133).

Inscrevemos-nos nesse movimento de ideias para explorar, aqui, um de seus resultados: o de que as noçôes articuladas de paradigmas e trajetórias tecnológicos 
oferecem perspectivas de compreensão dinâmicas e complexas, fundamentais para heurísticas de intervenção quando os problemas estratégicos de desenvolvimento reclamam reorientações nas bases institucionais de produção e distribuição de conhecimento, como é claramente o caso da Amazônia.

\subsection{0 encaminhamento teórico 2: paradigmas tecnológicos como relações sociedade-natureza - uma aproximação no que se refere à Amazônia}

Dosi define paradigma tecnológico “[...] como um 'modelo' ou um 'padrão' de solução de problemas tecnológicos selecionados, baseado em princípios selecionados, derivados das ciências naturais e em tecnologias materiais selecionadas. [...] Ao mesmo tempo, paradigmas tecnológicos definem também alguma ideia de progresso" (Dosi, 2006:22-23). Um paradigma tecnológico se constitui, assim, (1) de uma "perspectiva" de definição de problemas relevantes à luz de uma noção de progresso e (2) de um conjunto de procedimentos - heurísticos - para resolver tais problemas. Por outro lado, um paradigma oferece uma possibilidade entre outras na organização da reprodução social, sendo sua existência concreta (histórica) (3) resultado de mecanismos de seleção (3.a) associados à dimensão econômica e (3.b) a outras dimensōes da vida em sociedade, em particular à cultura, à política e à ciência.

Uma trajetória tecnológica, nessa perspectiva, é um padrão usual de atividades que resolvem, com base em um paradigma tecnológico, os problemas produtivos e reprodutivos que confrontam os processos decisórios de agentes concretos em contexto específico nas dimensões econômica, institucional e social (Dosi, 2006:22-23). As particularidades do contexto econômico se estabelecem nos critérios econômicos "[...] que agem como seletores definindo mais ou menos precisamente o trajeto concreto seguido no interior de um conjunto maior de possibilidades" (Dosi, 2006:23). Considerando o elevado nível de incerteza que cerca a adoção de tecnologias, o ambiente institucional assume particular relevância na configuração de trajetórias tecnológicas, desde o interesse econômico das organizaçóes, passando pelas respectivas histórias e acúmulos de expertise, até variáveis institucionais strictu sensu, como agências públicas e interesses geopolíticos (Dosi, 2006:24-25).

Além dos condicionantes econômicos, sociais e políticos, realçados por Dosi "[...] como os fatores prováveis a operar como forças focais na delimitação das direçôes que toma o desenvolvimento tecnológico" (2996:25), sublinhamos o contexto ecológico - o papel da base natural na configuração de paradigmas tecnológicos e suas trajetórias. Os problemas a que se refere um paradigma tecnológico são, 
por suposto, problemas tecnológicos, isto é, problemas da relação entre trabalho humano, objetivado por um modo de produção, e seu objeto último, a natureza. Nos processos industriais, a natureza está presente dominantemente como natureza morta. Mas há inúmeras atividades produtivas que se realizam em interação com a natureza viva. Nesse caso, a capacidade produtiva da natureza codetermina o resultado do processo produtivo. Como matéria-prima, a natureza é objeto inerte do trabalho humano; como uma força produtiva, capacidade ativa e, como tal, um capital: o capital natural.

A natureza vista como matéria-prima é tratada na sua condição mediata, como matéria genérica intercambiável e substituível - nesse caso, não é a capacidade produtiva das relações próprias e localizáveis de suas manifestações, como biomas ou ecossistemas, mas os componentes dessas relações individualmente, como matériaprima, como matéria genérica, que entra nos processos produtivos. Nesse caso se igualam: (1) a madeira que é retirada de um bioma e (2) o solo que se usa apenas como suporte de uma fórmula química que se integra sob controle com um clima de estufa, ou um pacote tecnológico fechado.

Como capital, força produtiva, a natureza é meio de produção imediato pela qualidade ímpar das suas manifestações originárias, é dizer, pelas particularidades de uma natureza (para si, na tradição hegeliana, encampada por Marx), que possam constituir valores de uso próprios, por seus atributos únicos. Isso acontece quando certa configuração das relações entre elementos vitais da natureza, configuração essa espacialmente delimitada e intransportável, é utilizada em um processo produtivo particular. Nesse caso, pode ser vista (1) como um ecossistema originário, um bioma, que, por ser preservado em sua complexidade, produz com exclusividade valores de uso capazes de atender necessidades humanas ou (2) como um ambiente edafoclimático, isto é, uma certa interação particular entre solo e clima a permitir a produção alternativa e excludente de valores de uso em sistemas simplificados (agrícolas, pecuários, silviculturais) com o propósito de maximizar a produção de biomassa por unidade de tempo/espaço.

A presença imediata da natureza como força produtiva faz a principal diferença entre a agricultura, ou melhor, entre os setores da produção rural e a indústria. Isso tem tido grande importância no tipo de dinâmica tecnológica que o desenvolvimento da sociedade capitalista vem produzindo nesses setores, pois à razão industrialista (industrial-capitalista) importa reduzir essa presença e controlar o seu significado. Tal esforço é central e em torno dele tem-se organizado o paradigma da modernização da agricultura, como sua industrialização. Goodman, Sorj e Wilkinson (1988) 
demonstram duas grandes trajetórias de industrialização do rural: a representada por um conjunto de soluções tecnológicas que se sucedem como esforço industrial de apropriação de papéis desempenhados pela natureza e outra por um conjunto de soluçôes que buscam substituir produtos da natureza viva por produtos inorgânicos e obtidos em laboratório (isto é, industrialmente). Hayamy e Ruttan (1980), por seu turno, observam que nesses processos a mecânica e a química têm papéis destacados, sendo a primeira o fundamento das soluções em que há abundância de terra e a segunda em que esse fator é limitado.

Em qualquer dos casos, domina, em nível global, um paradigma ou padrão tecnológico, que se afirma por conjuntos de soluções selecionadas pela eficiência demonstrada no controle da natureza, para que corresponda às necessidades industriais e capitalistas. Tais soluçôes se sucedem compondo trajetórias tecnológicas marcadas pelo uso intensivo da mecânica e da química e pela formação dos sistemas botânicos e biológicos homogêneos para isso necessários.

Tal paradigma "global" está presente na realidade amazônica em dois universos: o da produção de bens, controlado pelos agentes produtivos mediante seus critérios próprios de decisão, e o da gestão das políticas públicas, em que se destacam aquelas que condicionam a produção e difusão de conhecimento científico e tecnológico. Está, portanto, na prática produtiva e reprodutiva dos que operam os processos de uso da natureza, de que faz parte um conhecimento tácito difuso e culturalmente conformado, na prática dos que operam as organizaçôes de produção de conhecimento codificado e de transmissão das soluções tecnológicas daí derivadas, além de incorporado em meios de produção gerados com conhecimentos obtidos alhures.

Em tal perspectiva, a natureza (a base natural) é vista e tratada na condição de matéria-prima em dois estágios - no inicial, quando se desmonta o ecossistema para comercializar suas partes; e no final, quando a terra é um suporte descartável. A natureza é vista e tratada, também, como um capital natural, quando incorporada na condição de sistema edafoclimático para a produção agropecuária.

Todavia, não está sozinho na configuração da realidade agrária da Amazônia esse que chamaremos aqui de "paradigma agropecuário". Há formas de utilização da base natural da região que pressupõem a manutenção da natureza originária e configuram, por isso, um paradigma tecnológico - que trataremos como "paradigma extrativista"-, porquanto perspectiva particular do uso social dos recursos e de resolução dos problemas a isso afetos. As soluções daí derivadas organizam as trajetórias tecnológicas sobre as quais procuraremos discernir. 


\subsection{Encaminhamento metodológico}

O "paradigma agropecuário", como perspectiva de progresso ou desenvolvimento e conjunto de procedimentos que pressupõem a transformação industrial da natureza originária no atendimento de necessidades reprodutivas da sociedade, se desenvolve, na Amazônia, por um antagonismo de fundo com o "paradigma extrativista", que pressupõe a manutenção dessa mesma natureza originária. Eles se desenvolvem em concorrência, protagonizada por atores privados e organizações.

No interior de cada paradigma, confrontam-se trajetórias também em concorrência materializada no embate entre as estruturas que gerem os processos produtivos e suas instituições de suporte, em particular as que lhes são fonte de conhecimento e inovação.

Os critérios privados, mesmo ganhadores na disputa entre trajetórias, não desembocam necessariamente nos melhores resultados para o conjunto da sociedade. A divergência poderá crescer mediante uma perspectiva de progresso e modernidade balizada por máxima esperança de sustentabilidade ecológica e equidade social. Faz-se necessária a antecipação de tais inconsistências, a verificação das suas causas e inquirição das condições institucionais que as superem.

Para tanto, partindo da premissa de que há uma relação íntima e indissociável entre sujeito e objeto do conhecimento tecnológico, deve-se investigar, de uma parte, as estruturas produtivas que operam tal conhecimento; de outra, os espaços institucionais que os elaboram. Colocados no campo de visão os resultados de tal empreitada, poder-se-á proceder a um julgamento das convergências e divergências mediante uma perspectiva de progresso social, moderno porque dominada pelo ideário do desenvolvimento sustentável. Esta tem sido nossa orientação em um trajeto já longo de pesquisa (Costa, 2007a, 2006, 2005, 2001, 2000a, 1998, 1992), no qual este artigo é um passo adicional.

Amparados na explicitação da diversidade de agentes e estruturas que fundamentam a produção rural na região (seção 2), procurar-se-á delinear trajetórias tecnológicas no limite oferecido pelas estatísticas disponíveis (discutiremos esses limites em 2.1). O que nos levou a uma estratégia de trabalho que privilegia a observação das relações entre as trajetórias e seus produtos - levando bem longe a exploração da compreensão de que produtos são fenômenos das trajetórias (2.2). De modo que, observando as características econômicas da produção (2.2.1 a 2.2.4), as interaçôes que ocorrem entre os grupos de produtos e a distribuição espacial de sua ocorrência (2.2.5), a relação que apresentam com as instituições (2.2.6) e a forma 
como desenvolvem no tempo (2.2.7) se espera configurar, na seção 3, as trajetórias tecnológicas fundamentais na Amazônia - e visualizar como paradigmas tecnológicos se manifestam na região. Ao final se discutirão questões relativas ao futuro da Amazônia e as implicações nas políticas de C\&T que visam mudar "trajetórias indesejadas" em favor de "trajetórias desejadas" numa perspectiva de um desenvolvimento de outro tipo, isto é, com maior esperança de sustentabilidade. Nesse momento nos manteremos atentos para o alerta feito por Dosi, de que "podem ser muito difíceis tais mudanças, especialmente quando a trajetória é muito 'poderosa”' (Dosi, 2006:25).

\section{A diversidade estrutural na Amazônia e seus agentes: o ponto de partida das trajetórias}

Temo-nos esforçado em estabelecer a diversidade de agentes e estruturas que conformam a dinâmica agrária na região com base nas respectivas especificidades de razões e processos decisórios (racionalidades) que, por uma parte, emergem de relações sociais próprias, por outra, conformam relaçōes técnicas particulares, profundamente marcadas pela diversidade de fundamentos naturais e institucionais, que, por seu turno, formam o piso e o entorno de suas existências. O modelo relacional que nos orienta está esquematizado na Figura 1. Dois tipos básicos têm prevalecido:

Os agentes camponeses, caracterizados pela centralidade da família nos processos decisórios, seja como definidora das necessidades reprodutivas, que estabelecem a extensão e a intensidade do uso da capacidade de trabalho de que dispõe, seja como determinante no processo de apropriação de terras nas sagas de fronteira, para os quais a eficiência reprodutiva (Costa, 1995, 2005, 2007a, 2007b, 2007c) não elimina, mas subordina a eficiência marginal do capital (Keynes, 1970; Prado, 1993) nas decisões econômicas fundamentais.

Os agentes patronais, os quais dependem do trabalho assalariado e, por isso, do grau de desenvolvimento do mercado de trabalho, resultam de processos de apropriação da terra e dos recursos da natureza definidos pelo poder econômico de seus titulares, que se comportam orientados dominantemente por avaliações da eficiência marginal do capital.

Agentes camponeses e patronais têm modelos próprios de avaliação da consistência intertemporal e interespacial de suas decisões, que os diferenciam intrinsecamente em seus modos de produzir, ao par das capacidades respectivas de acesso a instituições e conhecimento: de acesso a capital natural (como propriedade, contestável ou não), a capital físico e a capital humano e social. Mutuamente determinadas, essas 
FIGURA 1

Fundamentos da diversidade de agentes no setor rural da Amazônia

\begin{tabular}{|c|c|c|c|c|c|c|c|}
\hline \multicolumn{3}{|c|}{$\begin{array}{c}\text { Agentes: racionalidade (genérica) } \\
\text { e } \\
\text { características (específicas) }\end{array}$} & & \multicolumn{2}{|c|}{$\begin{array}{c}\text { Natureza: percepção social } \\
\text { e características objetivas } \\
\text { da reprodução }\end{array}$} & \multicolumn{2}{|c|}{$\begin{array}{l}\text { Instituições: acesso à } \\
\text { natureza e a capital } \\
\text { tangível e intangível }\end{array}$} \\
\hline \multirow{4}{*}{ 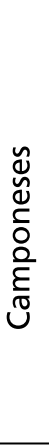 } & \multirow{4}{*}{$\begin{array}{l}\text { "Eficiência } \\
\text { reprodutiva" } \\
\text { subordina } \\
\text { "Eficiência } \\
\text { marginal do } \\
\text { capital" } \\
\text { (decisōes } \\
\text { pautadas e multi- } \\
\text { critério, tradeoff } \\
\text { média/variança } \\
\text { da renda, da } \\
\text { oferta/segurança } \\
\text { alimentar, etc.) }\end{array}$} & \multirow{2}{*}{$\begin{array}{c}\text { Consistência } \\
\text { intertemporal } \\
\text { das decisões } \\
\text { (sim/não) }\end{array}$} & \multirow{4}{*}{$\langle\vec{\gamma}$} & \multirow{2}{*}{$\begin{array}{c}\text { Natureza morta, } \\
\text { natureza como } \\
\text { matéria-prima }\end{array}$} & $\begin{array}{l}\text { Terra } \\
\text { firme }\end{array}$ & \multirow{2}{*}{$\begin{array}{l}\text { "Property } \\
\text { rights" } \\
\text { garantidos }\end{array}$} & $\begin{array}{l}\text { Acesso a } \\
\text { capital } \\
\text { dinheiro }\end{array}$ \\
\hline & & & & & Várzea & & $\begin{array}{c}\text { Acesso a } \\
\text { conheci- } \\
\text { mento } \\
\text { codificado }\end{array}$ \\
\hline & & \multirow{2}{*}{$\begin{array}{l}\text { Consistência } \\
\text { interespacial } \\
\text { das decisões } \\
\text { (sim/não) }\end{array}$} & & \multirow{2}{*}{$\begin{array}{l}\text { Natureza viva, } \\
\text { natureza como } \\
\text { força produtiva }\end{array}$} & $\begin{array}{l}\text { Terra } \\
\text { firme }\end{array}$ & \multirow{2}{*}{$\begin{array}{l}\text { Status de } \\
\text { fronteira }\end{array}$} & $\begin{array}{c}\text { Acesso a } \\
\text { capital } \\
\text { dinheiro }\end{array}$ \\
\hline & & & & & Várzea & & $\begin{array}{c}\text { Acesso a } \\
\text { conheci- } \\
\text { mento } \\
\text { codificado }\end{array}$ \\
\hline \multirow{4}{*}{$\begin{array}{l}\frac{n}{\pi} \\
\frac{1}{0} \\
0 \\
\frac{0}{\pi} \\
\frac{0}{0}\end{array}$} & \multirow{4}{*}{$\begin{array}{c}\text { "Eficiência } \\
\text { marginal do } \\
\text { capital" (renda } \\
\text { líquida } \\
\text { descontada) } \\
\text { subordina } \\
\text { "Eficiência } \\
\text { reprodutiva" }\end{array}$} & \multirow{2}{*}{$\begin{array}{c}\text { Consistência } \\
\text { intertemporal } \\
\text { das decisões } \\
(\operatorname{sim} / \text { não) }\end{array}$} & \multirow{4}{*}{$\langle i$} & \multirow{2}{*}{$\begin{array}{c}\text { Natureza morta, } \\
\text { natureza como } \\
\text { matéria-prima }\end{array}$} & $\begin{array}{l}\text { Terra } \\
\text { firme }\end{array}$ & \multirow{2}{*}{$\begin{array}{l}\text { "Property } \\
\text { Rights" } \\
\text { garantidos }\end{array}$} & $\begin{array}{c}\text { Acesso a } \\
\text { capital } \\
\text { dinheiro }\end{array}$ \\
\hline & & & & & Várzea & & $\begin{array}{c}\text { Acesso a } \\
\text { conheci- } \\
\text { mento } \\
\text { codificado }\end{array}$ \\
\hline & & \multirow{2}{*}{$\begin{array}{l}\text { Consistência } \\
\text { Interespacial } \\
\text { das decisões } \\
\text { (sim/não) }\end{array}$} & & \multirow{2}{*}{$\begin{array}{l}\text { Natureza viva, } \\
\text { natureza como } \\
\text { força produtiva }\end{array}$} & $\begin{array}{l}\text { Terra } \\
\text { firme }\end{array}$ & \multirow{2}{*}{$\begin{array}{l}\text { Status de } \\
\text { fronteira }\end{array}$} & $\begin{array}{c}\text { Acesso a } \\
\text { capital } \\
\text { dinheiro }\end{array}$ \\
\hline & & & & & Várzea & & $\begin{array}{l}\text { Acesso a } \\
\text { conheci- } \\
\text { mento } \\
\text { codificado }\end{array}$ \\
\hline
\end{tabular}

Fonte: desenvolvimento do autor.

diferenças estabelecem modos próprios de ver e usar a natureza: se como matériaprima ou como força produtiva - na condição de relações edafoclimáticas ou na condição de bioma florestal.

Numa análise que confrontou quatro modelos multivariados que explicitavam os fundamentos produtivos e os resultados da produção de 443.570 estabelecimentos rurais da região Norte, dos quais $93 \%$ camponeses e $7 \%$ patronais (para a metodologia de distinção estatística, ver Box 1), logramos demonstrar que tais diferenças caracterizam claramente dois "projetos" de desenvolvimento de base rural na Amazônia, os quais “[...]. diferenciam-se nas formas de tratamento do capital natural (cuja referência primordial é o bioma da floresta amazônica), [...] e nas proporções de uso de capital físico e de trabalho" (Costa, 2007a:141-142). Em análises institucionais 
precedentes, demonstramos também que tais projetos têm suportes institucionais distintos, baseados "[...] numa razão técnica incapaz de lidar, conceitual e operacionalmente, com o 'valor' da diversidade para um desenvolvimento duradouro na Região, desaparelhada para tratar com os atores capazes de gerir diversidade e com as manifestaçōes e resultados locais dessas capacidades" (Costa, 2005:144-145).

Agora nos colocamos duas questôes:

1) Podemos, com os dados que nos são disponiveis, decompor tais "projetos" em trajetórias e situá-las em paradigmas tecnológicos?

2) Podemos imbricar nessas categorias as questões relevantes de conhecimento e política?

Nos próximos segmentos nos dedicaremos a responder a esses quesitos e confrontar os resultados com perspectivas de desenvolvimento moderno e sustentável, com o propósito de julgar o que se faz para indicar o que se poderia fazer na conformação das bases de conhecimento adequadas.

\subsection{Os dados disponíveis e a noção de trajetória: o ponto e seu entorno}

Temos dois tipos de dados que cobrem o setor rural da totalidade da região Norte: os censos agropecuários, com mais de duas centenas de variáveis sobre relações de propriedade, relações sociais e técnicas, estruturas de produção e venda etc. e os acompanhamentos conjunturais, com periodicidade anual (produção agrícola municipal, produção extrativa municipal, produção pecuária municipal etc.).

Os censos são as mais amplas pesquisas com mesma metodologia que se dispõe e os acompanhamentos anuais, por sua vez, os mais amplos e sistematicamente levantados indexadores de algumas das variáveis constantes dos censos. Os dados de um censo referem-se, para cada variável, a pontos de trajetos percorridos pelos estabelecimentos. Sabemos que tais caminhos são conformados por ajustamentos contínuos naquela variável, processados no passado, que definirão tendencialmente seus próximos momentos. Mas, para aquela variável específica, só vemos o ponto. As questôes metodologicamente relevantes são: Podemos dizer algo mais além daquilo que vemos no ponto? Podemos dizer algo sobre o caminho do qual esse ponto é uma passagem, como se exige a partir das ideias apresentadas na introdução deste segmento?

A resposta a essas perguntas tem duas partes. A primeira depende do próprio censo; a segunda, da relação entre censo e os acompanhamentos conjunturais. Se $\mathrm{X}_{\mathrm{t}}$ 


\section{BOX 1}

A base de dados e a classificação por formas de produção

O meio eletrônico de publicação dos dados censitários tem permitido uma utilização bem mais ampla e flexivel das informaçôes censitárias do que a publicação em papel, não apenas pela velocidade de acesso, mas, sobretudo, pelo fato de permitir que se obtenham todas as tabelas padrão que apresentam os resultados do Censo, anteriormente só disponiveis para a unidade federativa, para todos os demais niveis regionais de agregação-para as mesorregiōes, para as microrregióes e para o município. Não obstante o fato de que a estrutura tabular mantém um elevado grau de rigidez, essa forma de publicação permite trabalhar com graus tanto maiores de flexibilidade, quanto mais se manejem os dados em esferas espaciais mais elementares. Isso porque, em qualquer dessas esferas, será possivel ter todas as variáveis constantes das tabelas básicas para todos os 15 "estratos de área total" usuais do Censo. E, no âmbito geográfico em que se esteja trabalhando, sempre se poderão considerar as médias de uma variável para os estratos como as das unidades produtivas médias respectivas e, assim tratados, cada estrato ganha a condição de um "caso" em um novo banco de dados passivel de retabulação e processamento, tendo a freqüiencia do estrato como um dos seus campos. Trabalhamos, aqui, com uma desagregação em âmbito de microrregião, para toda a Região Norte. Desse modo, manejamos um banco de dados de 960 "casos" (64 microrregióes multiplicadas por quinze estratos de área).

Essa metodologia aumentou muito as possibilidades de utilização das informaçōes, permitindo não só a edição de variáveis existentes e a criação de novas variáveis e indicadores com abrangência total, como a melhor operacionalização de conceitos-chave para a compreensão da realidade agrária em âmbito bem mais elementar, e, nesse sentido, estatisticamente bem mais abrangente do que nos havia sido possivel até então. Assim, distinguimos os casos entre camponeses e patronal, com base no tipo de força de trabalho utilizada. Esse critério é necessário e suficiente por razóes apresentadas em antes (sobretudo Costa, 2000b: 110-130). Do seguinte modo: para cada um dos 960 casos do banco - estratos de área x para a microrregião y - calculamos a força de trabalho total pela soma da força de trabalho familiar total mais força de trabalho de terceiros aplicado à produção. A força de trabalho familiar total = total da categoria do Censo "membros não remunerados da família maiores de 14 anos" mais a metade da categoria "membros não remunerados da família menores de 14 anos". A força de trabalho de terceiros foi obtida pela soma dos gastos com salários, com empreitas e outros contratos de prestação de serviço dividida pelo valor médio da diária prevalecente multiplicada por 300 dias médios de trabalho por ano. Se considerou "familiar" ou "camponês" o caso cuja participação relativa da força de trabalho de terceiros total estimada no total da força de trabalho não ultrapassou 1/2, e "patronal" o estabelecimento médio com força de trabalho de terceiros acima de 1/2.

Fonte: Costa 2007a. 
é uma variável do censo, com t representando o ano de levantamento, do mesmo modo que $\mathrm{XP}_{\mathrm{t}}$ e $\mathrm{XF}_{\mathrm{t}}$ o são, a primeira informando sobre o passado de $\mathrm{X}$ e a segunda sobre seu futuro, então posso dizer algo sobre a trajetória de $\mathrm{X}$ : ele está vindo de um provável $\mathrm{X}_{\mathrm{t}-\mathrm{n}}$, informado por $\mathrm{XP}_{\mathrm{t}}$, e, passando por $\mathrm{X}_{\mathrm{t}}$, indo para um provável $\mathrm{X}_{\mathrm{t}+\mathrm{m}}$, informado por $\mathrm{XF}_{\mathrm{t}}$, onde $n$ e $m$ são lapsos de tempo indefinidos, porém reais. Por outra parte, se $\mathrm{X}_{\mathrm{t}}$, no censo, tem em $\mathrm{x}_{\mathrm{t}}$ levantada em pesquisa conjuntural, porém sistemática, uma proxy, pode-se considerar - com margem de erro que depende da qualidade da pesquisa - que $\mathrm{X}_{\mathrm{t}-\mathrm{n}}=\mathrm{X}_{\mathrm{t}} \cdot\left(\mathrm{x}_{\mathrm{t}-\mathrm{n}} / \mathrm{x}_{\mathrm{t}}\right)$ e $\mathrm{X}_{\mathrm{t}+\mathrm{n}}=\mathrm{X}_{\mathrm{t}} \cdot\left(\mathrm{x}_{\mathrm{t}+\mathrm{n}}\right) /\left(\mathrm{x}_{\mathrm{t}}\right)$, sendo $n \mathrm{um}$ lapso de tempo definido e real.

Usaremos adiante exaustivamente essas possibilidades metodológicas.

\subsection{Trajetória tecnológica: um conceito operacional e a estratégia da pesquisa}

Seguindo orientação teórica já detalhada acima, a noção de paradigma tecnológico aplicada à produção rural na Amazônia está aqui referida às atitudes fundamentais mediante a base natural da região: num extremo, as formas de produção que pressupōem a manutenção da natureza originária (o bioma florestal amazônico); noutro, as formas de produção que pressupõem a transformação da natureza originária. Entre o primeiro, que "chamamos paradigma extrativista", e o último, que chamamos "paradigma agropecuário", há posturas intermediárias que conformariam um "paradigma agroflorestal".

De tais posturas derivam as soluções técnicas e institucionais (os conjuntos de procedimentos que se constroem no tempo em concatenaçōes próprias de trajetórias, em que as decisões passadas influem no presente, e estas condicionam o futuro) para os processos produtivos realizados em condições particulares que, ao tempo que suprem as necessidades sociais de um conjunto dado de produtos rurais, são soluções moldadas para atender aos anseios privados dos agentes que gerem esses processos produtivos. E modelos complexos demonstram que, quanto mais um conjunto particular de soluções se torna importante como supridor das necessidades sociais, tanto mais, portanto, venha ele a ocupar o espaço social do suprimento dessas necessidades, maior a capacidade de realização, por parte dos agentes envolvidos, de rendimentos adicionais (crescentes) provindos do ambiente institucional (Arthur, 1994). Essas interações dinâmicas entre necessidades sociais e privadas, de um lado, e procedimentos técnicos e institucionais, de outro, realizadas nos processos produtivos de produtos particulares, se fazem, assim, em confronto concorrencial entre as trajetórias tecnológicas, estas as formas particulares e concretas de realização de um paradigma tecnológico de realização de uma ontologia de relações com a natureza. 
Um resultado desse entendimento, de considerável valor experimental, é o de que toda produção se faz como parte de alguma trajetória - portanto, produtos são fenômenos de trajetórias. Por isso, qualificar a produção (para o que temos um número considerável de variáveis bem-informadas no censo e nas estatísticas anuais) pode ser caminho para se chegar à compreensão das trajetórias que lhes são subjacentes (as quais não se deixam ver a olho nu). Como corolário, há três noções importantes para esse trabalho. Primeiro, a relevância de um dado produto ou conjunto de produtos, ${ }^{3}$ nas variações da produção total revela a sua importância, e por essa via a relevância social (para o todo da economia em questão) da trajetória que lhe é subjacente seu peso na configuração da divisão social do trabalho. Segundo, a capacidade de um dado conjunto de produtos de compensar os gestores dos processos produtivos revela sua eficiência e, em consequência, a eficiência da trajetória de que participa na realização subjacente dos anseios privados - sua relevância microeconômica privada. Deve-se lembrar que esses dois pontos podem guardar relação dinâmica. Terceiro, se um grupo de produtos se revela fonte de investimentos, ele é base da capacidade de expansão da trajetória que lhe é subjacente.

Conhecidas a relevância social e privada dos grupos de produtos, bem como se eles se constituem como fonte de investimentos, oito combinações lógicas são possíveis, as quais permitem inferências na qualificação dos modos como participam das trajetórias que lhes fundamentam, tal como indicadas na última coluna da Tabela 1. Essas combinaçôes constituem interesse para análise em maior detalhe, o que será feito nas seçōes 2.2.1, 2.2.2, 2.2.3 e 2.2.4.

\subsubsection{Sobre a relevância social (macro) dos grupos de produtos}

As formas de produção prevalecentes no agrário da região amazônica, assentadas sobre peculiares relaçôes sociais (trabalho familiar e trabalho assalariado), distinguem-se entre si por seus fins e pelos meios utilizados para alcançá-los. Estruturam-se, isso posto, como combinações próprias das suas disponibilidades (as quais derivam de eventos

3 Daqui por diante esta será uma referência recorrente. Com ela se pretende designar o conteúdo empírico do tipo de informação relativa à produção disponível no Censo Agropecuário, que é o valor agregado da produção classificada por origem: se produção animal ou vegetal, e, no interior da primeira, se da pecuária de grande, de médio e pequeno porte; no interior da segunda, se de plantios de culturas temporárias, permanentes, silvicultura etc. Não seria errado presumir, desde o início, que, por trás desses conjuntos de produtos sob essas classificações, se encontram sistemas ou subsistemas de produção - presumimos, portanto, sistematicidades a priori desses conjuntos de produtos, per se, a serem integradas nos sistemas maiores pelas trajetórias que pretendemos delinear. Todavia, não explicitaremos tal presunção até dar outros passos na investigação que nos permitam qualificar melhor os grupos de produtos e, por essa via, aprender mais sobre natureza e forma dos sistemas que eventualmente representem ou integrem. 
TABELA 1

Atributos dos grupos de produtos e expectativa quanto às formas respectivas de participação nas trajetórias tecnológicas subjacentes

Atributos dos grupos de produtos

\begin{tabular}{|c|c|c|c|c|c|}
\hline $\begin{array}{l}\text { Possibi- } \\
\text { lidades }\end{array}$ & $\begin{array}{l}\text { Socialmente } \\
\text { relevante }\end{array}$ & $\begin{array}{l}\text { Compensação } \\
\text { privada } \\
\text { positiva }\end{array}$ & $\begin{array}{l}\text { Fonte de } \\
\text { investimento }\end{array}$ & & \\
\hline 1 & Verdadeiro & Verdadeiro & Verdadeiro & G1 & $\begin{array}{l}\text { Posição principal, influenciando na expansão } \\
\text { de modo consistente e com capacidade } \\
\text { endógena de desenvolvimento }\end{array}$ \\
\hline 2 & Verdadeiro & Verdadeiro & Falso & G2 & $\begin{array}{l}\text { Posição principal, influenciando na expansão } \\
\text { de modo consistente, porém sem capacidade } \\
\text { endógena de desenvolvimento }\end{array}$ \\
\hline 3 & Verdadeiro & Falso & Falso & G3 & $\begin{array}{l}\text { Posição principal, porém inconsistente } \\
\text { e decadente }\end{array}$ \\
\hline 4 & Falso & Falso & Falso & G4 & Decadente ou ad hoc ou experimental \\
\hline 5 & Falso & Verdadeiro & Verdadeiro & G5 & $\begin{array}{l}\text { Emergente com capacidade endógena } \\
\text { de desenvolvimento }\end{array}$ \\
\hline 6 & Falso & Falso & Verdadeiro & G6 & Subordinado, podendo constituir-se financiador \\
\hline 7 & Verdadeiro & Falso & Verdadeiro & G7 & $\begin{array}{l}\text { Principal, inconsistente ou subordinada como } \\
\text { financiador }\end{array}$ \\
\hline 8 & Falso & Verdadeiro & Falso & G8 & $\begin{array}{l}\text { Emergente, sem capacidade endógena de } \\
\text { desenvolvimento }\end{array}$ \\
\hline
\end{tabular}

Fonte: desenvolvimento do autor.

históricos em que mediações institucionais outras, que não apenas o mercado, têm fundamental importância) e ofertam, como resultado dessas configurações, produtos diferentes. As interações trabalho-natureza, mediadas por conhecimentos e meios materiais de produção, constituem os fundamentos técnicos das formas de produção. As diferentes composiçôes de produtos que formam o valor da produção final, por seu turno, expressam as formas como tais combinaçôes de disponibilidade se justificam socialmente - como as formas de produção participam da divisão social do trabalho organizada por mercados amplos - locais, regionais, nacional e mundial. 
As diferentes composições de produtos agregadas pelas formas de produção fundamentais para toda a região Norte serão expressas aqui por funções do tipo genérico:

$$
\begin{aligned}
& Y_{B}=\beta_{B P C}^{Y} \cdot Y_{P C}+\beta_{B P L}^{Y} \cdot Y_{P L}+\beta_{B P M}^{Y} Y_{P M}+\beta_{B P P}^{Y} \cdot Y_{P P}+\beta_{B C P}^{Y} \cdot Y_{C P}+ \\
& \beta_{B C T}^{Y} \cdot Y_{C T}+\beta_{B C H}^{Y} \cdot Y_{C H}+\beta_{B C S}^{Y} \cdot Y_{C S}+\beta_{B F M}^{Y} \cdot Y_{F M}+\beta_{B F N}^{Y} \cdot Y_{F N}
\end{aligned}
$$

onde a variável dependente é:

$\mathrm{Y}_{\mathrm{B}}=$ Valor Bruto de Produção (VBP) total da forma de produção em questão $(\mathrm{R} \$)$.

e as variáveis independentes são:

$\mathrm{Y}_{\mathrm{PC}}=$ Valor Bruto da Produção (VBP) da pecuária bovina: boi em pé (R\$).

$\mathrm{Y}_{\mathrm{PL}}=\mathrm{VBP}$ da pecuária bovina: leite e venda de matrizes e outros produtos (R\$).

$\mathrm{Y}_{\mathrm{PM}}=\mathrm{VBP}$ da pecuária de médios animais: basicamente suínos $(\mathrm{R} \$)$.

$\mathrm{Y}_{\mathrm{PP}}=\mathrm{VBP}$ da pecuária de pequenos animais: basicamente aves $(\mathrm{R} \$)$.

$\mathrm{Y}_{\mathrm{CP}}=\mathrm{VBP}$ das culturas permanentes $(\mathrm{R} \$)$.

$\mathrm{Y}_{\mathrm{CT}}=\mathrm{VBP}$ de culturas temporárias $(\mathrm{R} \$)$.

$\mathrm{Y}_{\mathrm{CH}}=\mathrm{VBP}$ de hortigranjeiros $(\mathrm{R} \$)$.

$\mathrm{Y}_{\mathrm{S}}=\mathrm{VBP}$ da silvicultura $(\mathrm{R} \$)$.

$\mathrm{Y}_{\mathrm{FM}}=\mathrm{VBP}$ do extrativismo vegetal: madeira em tora $(\mathrm{R} \$)$.

$\mathrm{Y}_{\mathrm{FNM}}=\mathrm{VBP}$ do extrativismo vegetal: produtos florestais não-madeireiros $(\mathrm{R} \$)$. 
Os coeficientes $\beta$ descrevem o modo como cada grupo de produtos e, consequentemente, o subsistema de produção a ele subjacente participam na variação da produção total $\mathrm{Y}_{\mathrm{B}}$ de um modo de produção: são indicações, isso posto, de sua relevância social, macro. Nossa análise distinguirá dois modelos lineares derivados de (1), o primeiro para os estabelecimentos com o atributo de "camponês" no banco de dados já apresentado (a regressão resultante refere-se ao modo de produção camponês na região Norte), caracterizado pelo conjunto de coeficientes $\left\{\beta_{Z}^{C}\right\}$, e outro para os estabelecimentos com atributo de "patronal" (a regressão resultante refere-se ao modo de produção patronal na região Norte), caracterizado pelo conjunto de coeficientes $\left\{\beta_{Z}^{P}\right\}$, onde $\beta_{Z}^{C}$ e $\beta_{Z}^{P}$ são os coeficientes padronizados (Standardized Regression Coefficients) das regressões lineares derivadas de (1) expressas em $z$-scores, isto é, não no seu valor original, mas, sim, no número de desvios-padrão em torno da média (Bühl \& Zöfel, 1996:197-198; Backhaus et al., 2000:18-19; Hair et al., 1998:147).

Por exemplo, $\beta_{\mathrm{BPC}}^{\mathrm{C}}$ corresponde ao número de desvios-padrão que $\mathrm{Y}_{\mathrm{B}}^{\mathrm{C}}$ varia em torno de sua média para uma variação de 1 desvio-padrão em $\mathrm{Y}_{\mathrm{PC}}^{\mathrm{C}}$ em torno da sua própria média, enquanto a soma de todos os coeficientes $\beta^{\complement}$ em $\mathrm{Y}_{\mathrm{B}}^{\mathrm{C}}$ representaria o número de desvios-padrão que este variaria em torno da sua média, quando todas as variáveis variassem 1 desvio-padrão e, assim, podem ser comparados diretamente na explicação do que ocorre em $\mathrm{Y}_{\mathrm{B}}^{\mathrm{c}}$.

\subsubsection{Influência dos grupos de produtos na rentabilidade: sua relevância privada}

A composição da produção, tal como a encontramos no momento do censo, expressa ajustamentos processados cumulativamente para atender às necessidades sociais, como argumentamos acima. Contudo, a composição da produção também reflete finalidades das formas de produção na ótica privada, isto é, na perspectiva de seus gestores. Isso quer dizer que se espera uma indução no processo de mudança que se faz referido também às razões dos agentes e às condições objetivas a partir das (e sobre as) quais operam. Tais condiçôes são internas a cada unidade produtiva, isto é, legadas pela vivência particular de cada uma em processos históricos da formação social da região; ou são externas, relacionando-se com cada unidade por iniciativa de seus controladores, mas pela via do mercado ou de outras instituiçôes. Ajustada pela interação desses vetores, a composição da produção que reflete as necessidades privadas dos gestores dos processos produtivos pode ser expressa pela função: 


$$
\begin{aligned}
& Y_{L}=\beta_{L P C}^{Y} \cdot Y_{P C}+\beta_{L P L}^{Y} \cdot Y_{P L}+\beta_{L P M}^{Y} Y_{P M}+\beta_{L P P}^{Y} \cdot Y_{P P}+\beta_{L C P}^{Y} \cdot Y_{C P}+ \\
& \beta_{L C T}^{Y} \cdot Y_{C T}+\beta_{L C H}^{Y} \cdot Y_{C H}+\beta_{L C S}^{Y} \cdot Y_{C S}+\beta_{L F M}^{Y} \cdot Y_{F M}+\beta_{L F N}^{Y} \cdot Y_{F N}
\end{aligned}
$$

$\mathrm{Na}$ função (2) os valores das variáveis independentes são os mesmos da função (1), enquanto a variável dependente $-Y_{L}-$ corresponde à renda líquida (VBP total menos Custo da Produção Total), isto é, a remuneração privada dos agentes controladores dos estabelecimentos considerados. Assim especificada, a função (2) é uma função de desempenho, cuja regressão nos moldes apresentados descreve a forma como o grupo de produtos considerados atuam na remuneração dos gestores. Enquanto a função (1), uma função de produto, expressa o resultado social (total) de uma divisão social do trabalho, a função (2) expressa de que modo os resultados que importam aos agentes privados, suas remunerações, dependem de tal estruturação. A mesma variável independente $Y_{P C}$, que na regressão da função (1) influencia $\beta_{B P C}^{Y}$ na variação da produção total, mediante a regressão da função (2), influencia $\beta_{L P C}^{\curlyvee}$ na variação da rentabilidade líquida dos estabelecimentos.

\subsubsection{Influência dos grupos de produtos nos investimentos: fontes endógenas e exógenas}

Os investimentos fundamentam a dinâmica das formas de produção e das trajetórias que organizam - garantem sua expansão.

Os investimentos podem ser analisados pela ótica da sua fonte. Isto é, por um lado, como uma função da renda gerada na economia em questão; por outro, como uma função das disponibilidades exógenas representadas por outras fontes de financiamento. Considerando que a renda é diretamente correlacionada com o Valor Bruto da Produção e, por isso, se forma basicamente orientada pelo que se descreveu na relação (1) e, ainda, que os créditos bancários indicam a participação das fontes exógenas de financiamento, tem-se:

$$
\begin{aligned}
& I_{F}=\beta_{F P C}^{I} \cdot Y_{P C}+\beta_{F P L}^{I} \cdot Y_{P L}+\beta_{F P M}^{I} Y_{P M}+\beta_{F P P}^{I} \cdot Y_{P P}+\beta_{F C P}^{I} \cdot Y_{C P}+ \\
& \beta_{F C T}^{I} \cdot Y_{C T}+\beta_{F C H}^{I} \cdot Y_{C H}+\beta_{F C S}^{I} \cdot Y_{C S}+\beta_{F F M}^{I} \cdot Y_{F M}+\beta_{F F N}^{I} \cdot Y_{F N}+\beta_{F C}^{I} \cdot C_{I}
\end{aligned}
$$

em que $\mathrm{I}_{\mathrm{F}}$ é o volume de investimentos observado em função dos grupos de produtos de (1) e (2) e do volume de crédito para investimentos obtido $\left(\mathrm{C}_{\mathrm{I}}\right)$. Mantido o 
método já apresentado, os coeficientes $\beta$ das variáveis $Y$ nas regressóes resultantes são medidas da participação dos grupos de produtos nas oscilações de investimentos (uma medida da participação de $\mathrm{Y}$ na variação do investimento); da variável $\mathrm{C}_{\mathrm{I}}$, medida da participação do crédito nessas variações. A essa função denominaremos investimento-fonte.

\subsubsection{Qualificação dos grupos de produtos}

Os coeficientes das regressóes discutidas acima, obtidos a partir da base de dados separada em dois sets em função da forma de produção (ver Box 1), compõem duas matrizes de valores de $\left[\beta_{\text {zij }}^{p}\right]$ e $\left[\beta_{\text {zij }}^{C}\right.$, correspondendo, respectivamente, à forma de produção patronal (primeira parte da Tabela 2) e à forma camponesa (segunda parte da Tabela 2). Nessa notação, $i$ denota um grupo de produtos que compõe a produção total da forma de produção e $j$ um dos três tipos de função, conforme especificado na Tabela 2. Usamos esses valores para estabelecer os atributos dos grupos de produtos de acordo com o indicado na Tabela 1: quanto ao peso e importância na variação da produção total - relevância social; quanto à rentabilidade privada e quanto à endogeneidade das fontes de recursos para investimento. Os atributos resultaram das seguintes condições:

1) Para qualificar um grupo de produtos segundo o atributo "Socialmente relevante" (Tabela 1), utilizou-se o seguinte critério: se $\beta_{i 1}^{P}>0,1$, então "Verdadeiro"; de outro modo "Falso" ( $i=1, \ldots, 10$, ver Tabela 2$)$. Arbitrou-se, portanto, que serão considerados de relevância macro (social) os grupos de produtos cujos VBP variam na mesma direção que o VBP total ${ }^{4}$ e em intensidade relativa (número de desvios-padrão) correspondente a pelo menos $10 \%$ daquela variação. Sete grupos de produtos entre os estabelecimentos patronais e seis entre os camponeses apresentaram-se como relevantes, com destaque para a pecuária de corte, silvicultura e culturas temporárias, entre os primeiros, e culturas temporárias, culturas permanentes e pecuária de leite, entre os últimos.

2) Para qualificar um grupo de produtos conforme o atributo "Compensação privada positiva", procedeu-se ao seguinte teste: se $\left(\beta_{i 2}^{P} / \beta_{i 1}^{P}\right)>0$, então "Verdadeiro", de outro modo, "Falso". Dado que $\beta_{i 1}^{P}$ é sempre positivo (ver nota

4 A rigor, as regressões especificadas pelas funções de tipo (1) produzirão betas necessariamente positivos, dado que os valores estatísticos da variável dependente são totalizações das variáveis independentes. 
4), isso significa que serão considerados consistentes com os fins privados os grupos de produtos cujos VBP influem positivamente na variação da renda líquida total (a variação da sua produção influi diretamente proporcional na rentabilidade total). Significa, também, que, mais que a medida absoluta da influência na variação da renda líquida, importa sua expressão relativa mediante a influência que o mesmo grupo de produto exerce na variação do VBP total. Esse resultado diz muito sobre a força de expansão e sobre a consistência da relevância social com os anseios privados. Quatro são, pois, as situações a considerar:

a) Os grupos de produtos inconsistentes na perspectiva privada - quando se expandem, reduzem a rentabilidade privada. Dos produtos relevantes, este é o caso dos que resultam das culturas temporárias e permanentes entre os estabelecimentos patronais e da silvicultura entre os camponeses.

b) Valores de $\left(\beta_{i 2}^{P} / \beta_{i 1}^{P}\right) \cong 1$ indicam situações em equilíbrio e expansão com rendimento constante. É o caso dos produtos da pecuária de corte e da avicultura entre os estabelecimentos patronais e da pecuária leiteira entre os camponeses.

c) Valores $0<\left(\beta_{i 2}^{P} / \beta_{i 1}^{P}\right)<1$ indicam situações fora do equilíbrio, nas quais o VBP do grupo de produtos varia com maior intensidade que a renda líquida total dele derivada, o que aponta para expansão com rentabilidade decrescente. Tanto mais próximos de zero, maior a inconsistência da rentabilidade privada diante da relevância social que esses valores revelam e menor a força de expansão do grupo de produtos em questão. Enquadram-se nesse caso os produtos provindos da silvicultura entre os estabelecimentos patronais e das culturas permanentes entre os camponeses.

d) Valores $\left(\beta_{i 2}^{P} / \beta_{i 1}^{P}\right)>1$, ao contrário, indicam situações fora do equilíbrio, nas quais a influência da variação do VBP do grupo de produtos na rentabilidade total é maior que no VBP total, o que indica rentabilidade crescente associada ao grupo de produtos. Tanto maior o valor, maior a inconsistência da rentabilidade privada diante da relevância social que esses valores revelam e maior a força de expansão do grupo de produtos em questão. Este é o caso do extrativismo madeireiro e do extrativismo não-madeireiro, tanto entre formas patronais como camponeses de produção. Para estes últimos, é também o caso dos produtos provindos de culturas temporárias. 
3) Para a qualificação segundo o atributo "Fonte de investimento", procedeu-se ao seguinte teste: se $\beta_{i 3}^{P}>0$, então "Verdadeiro", de outro modo, "Falso". Isso significa que, se o grupo de produtos se expande, ele contribui para a ampliação do investimento global do modo de produção ele é, portanto, fonte de investimentos do modo de produção. Dos grupos de produtos relevantes, entre os estabelecimentos patronais, este é o caso dos produtos das culturas temporárias, da pecuária de leite e da silvicultura; entre os camponeses, da pecuária de corte e leiteira, das culturas permanentes e da silvicultura.

Quando combinados, esses resultados chamam a atenção para os grupos de produtos com atributo G1, que combinam os três atributos: são relevantes em termos macroeconômicos, apresentam rentabilidade privada e constituem fonte de investimento. Eles são, entre os estabelecimentos patronais, pecuária leiteira e silvicultura; entre os camponeses, pecuária de corte, pecuária de leite e culturas permanentes. Eles mostram uma capacidade de expansão consistente, endogenamente patrocinada, fonte de acumulação de capacidade produtiva.

Os resultados combinados chamam a atenção, também, para os grupos de produtos qualificados como G2: que combinam como verdadeiros os dois primeiros atributos - de relevância macro e consistência micro - sem apresentar interferência nos investimentos. Sobre eles se pode dizer que mostram força de expansão, porém não são objetos de acumulação de capacidade produtiva. É o caso dos produtos derivados da pecuária de corte, do extrativismo madeireiro e da avicultura, entre os estabelecimentos patronais, e, entre os camponeses, dos derivados de extrativismo madeireiro e não-madeireiro.

Os grupos de produtos qualificados como G7 são os que apresentam relevância macro e condição de fonte ou lócus de investimento, porém com rentabilidade contestável. É o caso dos produtos das culturas temporárias e das culturas permanentes entre os patronais.

O que podem representar essas diferentes características dos grupos de produtos para as trajetórias que lhes são subjacentes? Ou, visto de outro modo, como se combinam tais diferenças na definição das trajetórias que lhes são subjacentes? A isso nos dedicaremos no próximo segmento. 
TABELA 2

Coeficientes $\beta$ das regressões, atributos associados de qualificação dos grupos de produtos, cargas fatoriais das combinações dos grupos de produtos relativos às estruturas camponesas e patronais na região Norte

\begin{tabular}{|c|c|c|c|c|c|c|c|c|c|c|c|c|c|}
\hline \multirow[b]{3}{*}{ Grupos de produtos } & \multirow{3}{*}{$\begin{array}{c}\text { Coef. } \\
\beta\end{array}$} & \multicolumn{3}{|c|}{ Variáveis dependentes } & \multicolumn{3}{|c|}{$\begin{array}{l}\text { Atributos dos grupos } \\
\text { de produtos }\end{array}$} & \multirow{3}{*}{$\begin{array}{c}\text { Classe } \\
\text { dos } \\
\text { grupos } \\
\text { de } \\
\text { produtos }\end{array}$} & \multicolumn{5}{|c|}{$\begin{array}{l}\text { Cargas fatoriais (primeiros cinco } \\
\text { fatores ou componentes principais) }\end{array}$} \\
\hline & & $Y_{B}$ & $Y_{L}$ & I & \multirow[b]{2}{*}{$\begin{array}{c}\text { Social- } \\
\text { mente } \\
\text { rele- } \\
\text { vante }\end{array}$} & \multirow[b]{2}{*}{$\begin{array}{c}\text { Com- } \\
\text { pensa- } \\
\text { ção } \\
\text { privada } \\
\text { positiva }\end{array}$} & \multirow[b]{2}{*}{$\begin{array}{c}\text { Fonte } \\
\text { de } \\
\text { investi- } \\
\text { mento }\end{array}$} & & \multirow[b]{2}{*}{ C1 } & \multirow[b]{2}{*}{ C2 } & \multirow[b]{2}{*}{ C3 } & \multirow[b]{2}{*}{ C4 } & \multirow[b]{2}{*}{ C5 } \\
\hline & & 1 & 2 & 3 & & & & & & & & & \\
\hline \multicolumn{14}{|c|}{ Forma de produção patronal } \\
\hline Ext. não-madeireiro & 1 & $0,025^{a}$ & $0,079^{\mathrm{a}}$ & $-0,038^{b}$ & $\mathrm{~F}$ & $\begin{array}{c}V \\
(3,16) \\
V\end{array}$ & $\mathrm{~F}$ & G8 & & & & & \\
\hline Ext. madeireiro & 2 & $0,111^{2}$ & $0,170^{\mathrm{a}}$ & $-0,035^{c}$ & $\mathrm{v}$ & $\begin{array}{c}(1,53) \\
F\end{array}$ & $\mathrm{~F}$ & G2 & 0,407 & $-0,183$ & 0,119 & $-0,712$ & 0,525 \\
\hline Cult. temporárias & 3 & $0,363^{\mathrm{a}}$ & $-0,105^{a}$ & $0,651^{a}$ & $\mathrm{v}$ & $\begin{array}{c}(-0,29) \\
F\end{array}$ & $\mathrm{v}$ & G7 & 0,459 & $-0,206$ & 0,051 & 0,489 & 0,304 \\
\hline Pec. suínos & 4 & $0,012^{\mathrm{a}}$ & $-0,039^{c}$ & $-0,019^{a}$ & $\mathrm{~F}$ & $\stackrel{(-3,25)}{V}$ & $\mathrm{~F}$ & G4 & & & & & \\
\hline Pec corte bovina & 5 & $0,548^{a}$ & $0,507^{\mathrm{a}}$ & $-0,054^{a}$ & $\mathrm{v}$ & $\stackrel{(0,93)}{\vee}$ & $\mathrm{F}$ & G2 & 0,756 & $-0,284 \mid$ & $-0,002$ & 0,112 & $-0,032$ \\
\hline Pec. leite e matrizes & 6 & $0,119^{\mathrm{a}}$ & $0,308^{\mathrm{a}}$ & $0,492^{\mathrm{a}}$ & v & $\stackrel{(2,59)}{F}$ & $\mathrm{v}$ & G1 & 0,774 & 0,120 & 0,032 & 0,105 & $-0,336$ \\
\hline Cult. permanentes & 7 & $0,145^{a}$ & $-0,189^{a}$ & $0,069^{\mathrm{a}}$ & $\mathrm{V}$ & $(-1,30)$ & $\mathrm{v}$ & G7 & 0,342 & 0,664 & 0,141 & $-0,315$ & $-0,318$ \\
\hline Silvicultura & 8 & $0,516^{a}$ & $0,280^{\circ}$ & $0,031^{\mathrm{c}}$ & $\mathrm{v}$ & $\stackrel{(0,54)}{V}$ & $\mathrm{v}$ & G1 & $-0,148-2$ & $-0,083$ & 0,977 & 0,097 & $-0,33$ \\
\hline Hortigranjeiros & 9 & $0,004^{2}$ & $0,095^{b}$ & $-0,020^{c}$ & $\mathrm{~F}$ & $\begin{array}{c}(23,75) \\
\vee\end{array}$ & $\mathrm{F}$ & G8 & & & & & \\
\hline $\begin{array}{l}\text { Pec. aves } \\
\text { Crédito para } \\
\text { investimento }\end{array}$ & 10 & $0,287^{3}$ & $0,262^{\mathrm{a}}$ & $\begin{array}{r}-0,016^{\mathrm{c}} \\
0,273^{\mathrm{a}}\end{array}$ & $\mathrm{v}$ & $(0,91)$ & $\mathrm{F}$ & $\mathrm{G} 2$ & 0,072 & 0,715 & 0,021 & 0,289 & 0,053 \\
\hline $\mathrm{R}^{2}$ & & $1,000^{\mathrm{a}}$ & $0,682^{\mathrm{a}}$ & $0,862^{\mathrm{a}}$ & & & & $\begin{array}{l}\text { Variância } \\
(80,8 \%)\end{array}$ & 24,2 & 16,13 & 14,2 & 13,8 & 12,6 \\
\hline \multicolumn{14}{|c|}{ Forma de produção camponesa } \\
\hline Ext. não-madeireiro & 1 & $0,156^{\mathrm{a}}$ & $0,186^{\mathrm{a}}$ & $-0,079^{\mathrm{a}}$ & $\mathrm{v}$ & $\begin{array}{c}\mathrm{V} \\
(1,19) \\
\mathrm{V}\end{array}$ & $\mathrm{F}$ & $\mathrm{G} 2$ & 0,275 & 0,746 & $-0,009$ & 0,607 & $-0,011$ \\
\hline Ext. madeireiro & 2 & $0,178^{\mathrm{a}}$ & $0,200^{\mathrm{a}}$ & $-0,038^{a}$ & v & $\stackrel{(1,12)}{\vee}$ & $\mathrm{F}$ & G2 & 0,067 & 0,580 & 0,737 & $-0,334$ & 0,014 \\
\hline Cult. temporárias & 3 & $0,478^{\mathrm{a}}$ & $0,581^{\mathrm{a}}$ & $-0,082^{\mathrm{a}}$ & $\mathrm{V}$ & $(1,22)$ & $\mathrm{F}$ & $\mathrm{G} 2$ & 0,674 & 0,393 & $-0,440$ & $-0,296$ & 0,320 \\
\hline Pec. suínos & 4 & $0,022^{\mathrm{a}}$ & $0,017 b$ & $0,210^{\mathrm{a}}$ & $\mathrm{F}$ & $\stackrel{(0,77)}{\vee}$ & V & G5 & & & & & \\
\hline Pec corte bovina & 5 & $0,152^{\mathrm{a}}$ & $0,085^{\mathrm{a}}$ & $0,258^{\mathrm{a}}$ & $\mathrm{V}$ & $\stackrel{(0,56)}{\vee}$ & $\mathrm{v}$ & G1 & 0,788 & $-0,408$ & 0,267 & 0,155 & 0,219 \\
\hline Pec. leite e matrizes & 6 & $0,215^{\mathrm{a}}$ & $0,223^{a}$ & $0,416^{a}$ & $\mathrm{v}$ & $\stackrel{(1,04)}{V}$ & $\mathrm{v}$ & G1 & 0,810 & $-0,386$ & 0,282 & 0,125 & $-0,061$ \\
\hline Cult. permanentes & 7 & $0,225^{a}$ & $0,194 a$ & $0,184^{a}$ & v & $\begin{array}{c}(0,86) \\
F\end{array}$ & $\mathrm{v}$ & G1 & 0,845 & 0,149 & $-0,223$ & $-0,199$ & $-0,399$ \\
\hline Silvicultura & 8 & $0,005^{a}$ & $-0,005 c$ & $0,065^{\mathrm{a}}$ & $\mathrm{F}$ & $(-1,00)$ & V & G6 & & & & & \\
\hline Hortigranjeiros & 9 & $0,058^{\mathrm{a}}$ & $0,045 a$ & $-0,026^{b}$ & $\mathrm{~F}$ & $(0,78)$ & $\mathrm{F}$ & G8 & & & & & \\
\hline $\begin{array}{l}\text { Pec, aves } \\
\text { Crédito para } \\
\text { investimento }\end{array}$ & 10 & $0,097^{\mathrm{a}}$ & $0,008 c$ & $\begin{array}{l}0,020 \mathrm{c} \\
0,111^{\mathrm{a}}\end{array}$ & $\mathrm{F}$ & $(0,08)$ & $\mathrm{v}$ & G5 & & & & & \\
\hline$R^{2}$ & & $1,000^{\mathrm{a}}$ & $0,994^{\mathrm{a}}$ & $0,905^{\mathrm{a}}$ & & & & $\begin{array}{c}\text { Variância } \\
(96,9)\end{array}$ & 42,1 & 23,2 & 15,6 & 10,8 & 5,2 \\
\hline
\end{tabular}

Fonte: Censo agropecuário de 1995-1996.

a Significativo a $0 \%$; ${ }^{b}$ Significativo a $5 \%$; ${ }^{c}$ Não-significativo.

Obs.: Para regressões com $\mathrm{R}^{2}=1$, os valores $F$ e $t$ são muito altos e a significância em consequência é 0 . 


\subsubsection{Interação entre os diversos produtos ou grupos de produtos}

Até agora estudamos grupos de produtos como fenômenos que nos são apresentados pelas estatísticas do censo. Qualificamos-os isoladamente mediante atributos: se têm peso elevado, se são rentáveis, se fundamentam investimentos, essas são suas qualidades como grupos de produto. Como sabemos que esses grupos de produtos são expressōes de trajetórias, inferimos que eles subsidiarão as trajetórias de que fazem parte com esses seus atributos que nos foram revelados pela análise precedente. Mas isso não é suficiente para reconhecermos que trajetórias são essas. Isso porque as trajetórias (estruturas em reprodução evolutiva em contexto econômico e institucional específico, as quais emitem sinais em seu percurso) podem expressar-se em mais de um grupo de produto - podem emitir diferentes sinais de seu movimento. Precisamos ver, isso posto, se há combinações de sinais que possam, como um sistema de fenômenos, dizer mais sobre os processos e aparatos produtivos subjacentes: as trajetórias.

Assim, qualificados os grupos de produto quanto ao papel que podem desempenhar nas trajetórias de que fazem parte, as questôes que se colocam são: Em que medida e de que modo esses produtos ou grupos de produtos se relacionam entre si? Caracterizam tais relaçôes interdependência sistemicamente justificáveis, inteligíveis na perspectiva evolucionária que caracterizam as trajetórias?

Dois tipos de relaçôes podem ocorrer de modo a caracterizar interdependência e, assim, indicar participação em uma mesma trajetória: relações de sucessão e relações de concomitância entre grupos de produtos diferentes. No primeiro, um grupo de produtos evolui nutrindo-se, por assimilação e, portanto, anulação -, do outro; na segunda evolui nutrindo-se, por sinergismo - e, portanto, mútuo fortalecimento -, do outro. Há uma terceira relação - a de concorrência, em que um evolui concorrendo pelo espaço (físico ou de mercado) do outro. Nesse caso, os produtos ou grupo de produtos pertenceriam a trajetórias diferentes.

Verificar a interdependência ou concorrência entre os grupos de produtos e avaliar o significado no delineamento das trajetórias, propriamente, será a tarefa deste segmento. Para tanto, é necessário observar as estruturas de correlações existentes entre os dados de produção dos grupos de produtos. A análise fatorial constitui ferramenta importante para esse tipo de tarefa. Trata-se de técnica de análise estatística multivariada, que visa identificar estruturas subjacentes em um conjunto de variáveis observadas, permitindo dois tipos de resultados: a sumarização e a redução de dados (Backhau et al., 2000:252-327). 
Nos processamentos de sumarização, explicitam-se as variáveis latentes (os fatores) pelos padrōes de variabilidade das variáveis manifestas (reais) e as cargas fatoriais de cada variável em relação ao fator. Um fator é um construto, uma entidade hipotética, uma variável não-observada, cuja realidade reside apenas no fato de explicarem a variância de variáveis observadas. As cargas fatoriais obtidas são coeficientes que expressam o quanto uma variável observada está carregada ou saturada em um fator.

Em processamentos de redução, os fatores podem ser transformados em variáveis inteiramente novas, que podem ser incluídas em análises subsequentes. (Hair et al., 1998:95).

Submetemos à análise fatorial o VBP dos grupos de produtos que se mostraram, na análise acima, socialmente relevantes para a produção total: sete grupos da produção patronal (o extrativismo madeireiro, as culturas temporárias e as permanentes, a pecuária bovina de corte e a de leite, a silvicultura e a avicultura) e seis da produção camponesa (o extrativismo madeireiro e o não-madeireiro, as culturas permanentes e as temporárias, a pecuária de corte e a de leite). Como nas regressões já apresentadas, aqui também se usou para processamento o SPSS (Bühl \& Zöfel, 1996:369-376), condicionando o cálculo a 25 interações e a um número máximo de 5 fatores por análise. Cada fator indica uma interação entre grupos de produtos, que pode revelar uma trajetória; a relevância empírica do fator se deverá expressar na proporção da variância total que explica. As cargas fatoriais dos grupos de produtos nos fatores - os respectivos graus de importância e o sentido, se positiva ou negativamente, como cada grupo compõe o fator ou componente principal encontram-se nas cinco últimas colunas da Tabela 2.

Além das cargas fatoriais, utilizamos os resultados do processamento de redução que atribui, a cada elemento do conjunto de dados original (ver Box 1), pesos (scores) para cada um dos cinco fatores analisados: o peso de cada fator se torna uma variável do conjunto de dados. O fator de maior peso foi utilizado para qualificar o elemento, criando-se assim outra variável nova, agora discreta, cujos elementos designam esses fatores dominantes. De modo que se assinala, no conjunto de dados, a que combinação de grupos de produtos (que chamamos adiante de "Combinações C de grupos de produtos”), que podem caracterizar uma trajetória, cada unidade de informação (estabelecimentos em um mesmo estrato de área em uma microrregião), pertence. Cruzando a variável "Combinaçôes C de grupos de produtos" com a localização geográfica (mesorregião nos estados) dos estabelecimentos e formas de produção, utilizando o VBT total como variável descritiva, ganhamos informaçôes 
preciosas sobre a geografia das interações (ver resultados na Tabela 3); cruzando com as formas de produção e tendo como variável descritiva o VBP dos grupos de produtos, adquirimos informações importantes sobre a estrutura da produção por trás dessas "combinaçōes" (ver resultados na Tabela 4).

Combinando o que já sabemos sobre os grupos de produtos per se (suas classes de atributos $G$ ) e o que aprendemos sobre suas interações nos processamentos mencionados, podemos caracterizar as combinações $\mathrm{C}$ de modo a avançar na percepção de como participam das trajetórias das quais são, de algum modo, expressão. Assim:

1) Combinação patronal $C 1$ (o fator explica $24,2 \%$ da variância total na análise fatorial) - considerando-se as cargas fatoriais (Tabela 2, coluna $\mathrm{C} 1$, forma de produção patronal), pode-se supô-la correspondendo a, ou participando de, uma trajetória comandada pela pecuária de corte, complementada pela produção de leite e matrizes e por culturas temporárias (estas últimas como fontes de investimentos, de acordo com o que indica sua classe G7) e pela extração madeireira (como suporte de rentabilidade - indicada pela classe de atributos G2). Tal combinação, cujo VBP representava $17 \%$ do VBP agropecuário total da região Norte em 1995 (ver Tabela 7), se desenvolve de modo altamente concentrado nos estados de Tocantins $(50 \%$ de seu VBP, dominantemente na mesorregião ocidental do Tocantins - 47\%) e Pará ( $41 \%$ do VBP, dominantemente no sudeste paraense - 31\%). Conforme a Tabela 4, a estrutura da produção média dos estabelecimentos aí posicionados, em toda a região, é composta por $66 \%$ da pecuária de corte, $14 \%$ da de leite e matrizes, $10 \%$ de culturas temporárias. As culturas permanentes, com $3 \%$, e a produção de madeira, com $2 \%$, são produçôes residuais.

2) Combinação patronal C2 (explica $16,1 \%$ da variância total na análise fatorial) comandada por culturas permanentes, de rentabilidade contestada, complementada por avicultura e pecuária bovina, desenvolve-se dominantemente no Pará, onde realiza $67 \%$ do seu produto, do que $35 \%$ na Região Metropolitana de Belém. Manifesta-se, também, no Amazonas e em Rondônia - com 10\% do VBP que produz. A estrutura da produção do estabelecimento médio aí detectado se assenta em proporçōes iguais nas culturas permanentes (30\% do VBP) e na produção de aves (30\%), além de pecuária bovina de corte (17\%) e leite (11\%).

3) Combinação patronal C3 ( $14,2 \%$ da variância total) - comandada por silvicultura. Desenvolve-se no Amapá (82\%) e no Pará (18\%). A produção é, nesse caso, especializada, $100 \%$ centrada em silvicultura. 
4) Combinação patronal C4 (13,8\% da variância total na análise fatorial) comandada por culturas temporárias relativamente isoladas, ou compondo em parte com a avicultura (milho para ração) ou com a pecuária de corte. Nessa condição, poderia ser um estágio primário da Combinação patronal C1, uma vez que se desenvolve como nas mesmas regiões daquela: principalmente no Tocantins (38\%, do que $25 \%$ no Tocantins ocidental) e no Pará (26\%, dos quais $20 \%$ no sudeste paraense). A impressão de que se trata de um estágio inicial da Combinação patronal C1 é reforçada pelo fato de que as estruturas de produção, não obstante apresentarem a maior participação de culturas temporárias entre todas da produção patronal (29\% do VBP), mostram grande concentração em pecuária de corte $(50 \%)$.

5) Combinação patronal C5 (explica $12,6 \%$ da variância total na análise fatorial) - extração de madeira relativamente isolada ou compondo com culturas temporárias. Aqui, também, se parece tratar de um estágio inicial de Combinação patronal $\mathrm{C} 1$, posto que se manifesta particularmente nas mesmas regiōes do Pará (62\%, do que 33\% no sudeste paraense). Mas também se manifesta em Rondônia (21\%). A estrutura produtiva média dos estabelecimentos corrobora a impressão de que se trata aqui também de um estágio inicial da Combinação patronal C1, uma vez que, apesar de apresentar a maior dependência de extração madeireira (17\%) de todas as combinações encontradas na forma de produção patronal, apresenta, como no caso anterior, elevada concentração em pecuária de corte $(46 \%)$.

6) Combinação camponês $C 1$ (explica $42,1 \%$ da variância total da análise fatorial) - esse fator parece expressar uma trajetória comandada pela combinação de culturas permanentes e da pecuária de leite, ambas com atributo G1 - expansão com rendimento constante e investimento endógeno. A pecuária para carne e as culturas temporárias se mostram importantes na combinação, porém complementares. Essa combinação, cujo VBP representava 24,6\% do VBP agropecuário total da região Norte em 1995 (ver Tabela 7), se desenvolve nos estados de Rondônia (35\% de seu VBP) e Pará [24\% do VBP, dominantemente no nordeste paraense (13\%), mas também no sudeste paraense (7\%)]. Conforme a Tabela 4, a estrutura da produção média, em toda a região, é conformada por culturas permanentes (23\%), leite (16\%) e culturas temporárias (34\%).

7) Combinação camponês C2 (explica $23,2 \%$ da variância total) - uma das duas combinações ancoradas em extrativismo não-madeireiro, cujo atributo G2 indica 
consistência quanto ao significado e rentabilidade, sem, contudo, representar lócus ou fonte de investimentos -, tem presença e sentido, mas não base para expansão. Tem expressão bastante difusa, com manifestação mais acentuada sob as condições particulares da sub-região estuarina da mesorregião nordeste paraense (26\%) e nos campos de Marajó (17\%), mas também no sudeste paraense (13\%) e Região Metropolitana de Belém (6\%), no Pará (63\%); no Amazonas (33\%), sobretudo na mesorregião centro-amazonense (15\%). A estrutura da produção média para toda a região se assenta nas culturas temporárias (47\%), culturas permanentes (19\%), extrativismo não-madeireiro (15\%) e extrativismo madeireiro (9\%).

8) Combinação camponês C3 (15,6\% da variância total) - combina extrativismo madeireiro, pecuária de corte e de leite, esta última apresentando atributo G1, constituindo objeto e fonte de investimentos e acumulação de capacidade produtiva. Ocorrem fundamentalmente em Marajó (44\%) e no baixo Amazonas, no Pará, (74\%), e em Rondônia (11\%). No estabelecimento médio, a produção madeireira representa $42 \%$ do VBP, a de culturas temporárias, $18 \%$; a produção de culturas permanentes e de pecuária leiteira representam, respectivamente, $9 \%$ e $10 \%$. As características da combinação indicam a possibilidade de ser estágio inicial da Combinação camponês C1.

9) Combinação camponês C4 (10,8\% da variância total) - trata-se da combinação onde o extrativismo não-madeireiro apresenta maior participação, com interaçóes tênues com a pecuária de corte e de leite. Ocorre principalmente no sudeste paraense (18\%), também em Marajó (14\%) e na sub-região estuarina do nordeste paraense (14\%). Expressa-se de modo importante no Acre (7\%) e difuso no Amazonas (9\%). A estrutura da produção se esteia em $26 \%$ de produtos do extrativismo não-madeireiro, em outros $26 \%$ de culturas temporárias, em culturas permanentes e na pecuária de leite ( $12 \%$ e $8 \%$, respectivamente) e $10 \%$ de pequenos animais.

10) Combinação camponês C5 (explica 5,2\% da variância total) - representado por interaçóes pouco significativas entre culturas temporárias e pecuária de corte. Manifesta-se particularmente no Pará (21\%, dos quais $15 \%$ no sudeste paraense e $6 \%$ no nordeste paraense) e em Tocantins (20\%). A estrutura da produção é concentrada em culturas temporárias (52\%), pecuária de corte (15\%), pecuária de leite e culturas permanentes ( $12 \%$ e $8 \%$, respectivamente). 
TABELA 3

Distribuição geográfica de ocorrência das Combinações $C$ dos grupos de produtos observada pela distribuição percentual do VBP por mesorregiões e estados

\section{Localização geográfica}

\section{Combinações (fatores) por forma de produção}

Patronal

Camponês

Total

\begin{tabular}{|c|c|c|c|c|c|c|c|c|c|c|c|}
\hline Mesorregião & $\mathrm{C} 1$ & $\mathrm{C} 2$ & C3 & $\mathrm{C} 4$ & $\mathrm{C} 5$ & $\mathrm{C} 1$ & $\mathrm{C} 2$ & C3 & $\mathrm{C} 4$ & C5 & \\
\hline Vale do Acre & & $3 \%$ & & $3 \%$ & $4 \%$ & $3 \%$ & & & $6 \%$ & $5 \%$ & $3 \%$ \\
\hline Vale do Juruá & & & & & $1 \%$ & & & & $1 \%$ & 1 & $2 \%$ \\
\hline Norte do Amapá & & & & $2 \%$ & & & & $1 \%$ & $1 \%$ & & $0 \%$ \\
\hline Sul do Amapá & & $5 \%$ & $82 \%$ & $1 \%$ & & & $3 \%$ & $5 \%$ & $3 \%$ & & $3 \%$ \\
\hline Centro amazonense & $1 \%$ & $11 \%$ & & $2 \%$ & $3 \%$ & $13 \%$ & $15 \%$ & $3 \%$ & $2 \%$ & $14 \%$ & $9 \%$ \\
\hline Norte amazonenense & & & & & & & $8 \%$ & & $3 \%$ & $1 \%$ & $1 \%$ \\
\hline Sudoeste amazonenense & & & & & $3 \%$ & $4 \%$ & $5 \%$ & & $2 \%$ & $6 \%$ & $3 \%$ \\
\hline Sul amazonense & & & & & $1 \%$ & & $5 \%$ & $4 \%$ & $2 \%$ & $11 \%$ & $3 \%$ \\
\hline Baixo Amazonas & $1 \%$ & $5 \%$ & $18 \%$ & $1 \%$ & $3 \%$ & 1 & & $17 \%$ & $3 \%$ & $3 \%$ & $5 \%$ \\
\hline Marajó & $3 \%$ & & & & $3 \%$ & & $17 \%$ & $44 \%$ & $14 \%$ & & $5 \%$ \\
\hline Metropolitana de Belém & & $35 \%$ & & & $7 \%$ & $2 \%$ & $6 \%$ & & 1 & & $4 \%$ \\
\hline Nordeste paraense & $2 \%$ & $14 \%$ & & $3 \%$ & $12 \%$ & $13 \%$ & $26 \%$ & & $14 \%$ & $6 \%$ & $10 \%$ \\
\hline Sudeste paraemse & $31 \%$ & $11 \%$ & & $20 \%$ & $33 \%$ & $7 \%$ & $13 \%$ & $8 \%$ & $18 \%$ & $15 \%$ & $16 \%$ \\
\hline Sudoeste paraense & $5 \%$ & $2 \%$ & & $2 \%$ & $6 \%$ & 1 & & $5 \%$ & $2 \%$ & & $4 \%$ \\
\hline Leste rondoniense & $7 \%$ & 1 & & 1 & $19 \%$ & $33 \%$ & $1 \%$ & $8 \%$ & $5 \%$ & $4 \%$ & $13 \%$ \\
\hline Madeira-Guaporé & $1 \%$ & & & $3 \%$ & $2 \%$ & $2 \%$ & $1 \%$ & $3 \%$ & $1 \%$ & $1 \%$ & $2 \%$ \\
\hline Norte de Roraima & & $2 \%$ & & $12 \%$ & & $1 \%$ & & $2 \%$ & $4 \%$ & $3 \%$ & $2 \%$ \\
\hline Sul de Roraima & & $1 \%$ & & $2 \%$ & & $1 \%$ & & $1 \%$ & $1 \%$ & & $1 \%$ \\
\hline Ocidental do Tocantins & $47 \%$ & & & $25 \%$ & $2 \%$ & & & & $5 \%$ & $14 \%$ & $12 \%$ \\
\hline Oriental do Tocantins & $4 \%$ & & & $13 \%$ & $2 \%$ & & & & $2 \%$ & $6 \%$ & $3 \%$ \\
\hline Total & $100 \%$ & $100 \%$ & $100 \%$ & $100 \%$ & $100 \%$ & $100 \%$ & $100 \%$ & $100 \%$ & $100 \%$ & $100 \%$ & $100 \%$ \\
\hline
\end{tabular}

Fonte: IBGE, Censo agropecuário de 1995-1996. Processamentos especiais do autor. 
TABELA 4

Composição da produção oriunda das combinações $C$ dos grupos de produtos observadas pela distribuição percentual do VBP por grupos de produtos e atividades

\begin{tabular}{|c|c|c|c|c|c|c|c|c|c|c|c|c|c|}
\hline \multirow[b]{3}{*}{$\begin{array}{l}\text { Grupos de } \\
\text { produtos }\end{array}$} & \multicolumn{13}{|c|}{ Combinações (fatores) por forma de produção } \\
\hline & \multicolumn{6}{|c|}{ Patronal } & \multicolumn{6}{|c|}{ Camponês } & \multirow{2}{*}{ Total } \\
\hline & $\mathrm{C} 1$ & $\mathrm{C} 2$ & C3 & $\mathrm{C} 4$ & $\mathrm{C5}$ & Total & $\mathrm{C} 1$ & $\mathrm{C} 2$ & $\mathrm{C} 3$ & $\mathrm{C} 4$ & $\mathrm{C} 5$ & Total & \\
\hline Corte & $65,7 \%$ & $17,3 \%$ & $0,0 \%$ & $50,0 \%$ & $45,8 \%$ & $50,3 \%$ & $10,9 \%$ & $0,8 \%$ & $6,2 \%$ & $5 \%$ & $15,4 \%$ & $9,6 \%$ & $23,7 \%$ \\
\hline Leite & $14,0 \%$ & $10,7 \%$ & $0,0 \%$ & $14,5 \%$ & $7 \%$ & $11,9 \%$ & $15,8 \%$ & $1 \%$ & $10,3 \%$ & $7,6 \%$ & $11,8 \%$ & $11,0 \%$ & $11,3 \%$ \\
\hline Permanentes & $3,5 \%$ & $30,2 \%$ & $0,0 \%$ & $1,7 \%$ & $2,2 \%$ & $6,3 \%$ & $23,4 \%$ & $18,6 \%$ & $8,5 \%$ & $11,5 \%$ & $7,5 \%$ & $15,7 \%$ & $12,5 \%$ \\
\hline Temporárias & $10,4 \%$ & $6,8 \%$ & $0,0 \%$ & $29,3 \%$ & $8,4 \%$ & $12,3 \%$ & $33,6 \%$ & $46,6 \%$ & $18 \%$ & $26,1 \%$ & $52,1 \%$ & $38,9 \%$ & $29,7 \%$ \\
\hline Madeireiro & $2 \%$ & $1,7 \%$ & $0,0 \%$ & $0,4 \%$ & $17,5 \%$ & $3,8 \%$ & $1,2 \%$ & $8,9 \%$ & $41,7 \%$ & $2,7 \%$ & $1,1 \%$ & $5,5 \%$ & $4,9 \%$ \\
\hline Não-madeireiro & $1,4 \%$ & $1,7 \%$ & $0,0 \%$ & $0,8 \%$ & $1,6 \%$ & $1,3 \%$ & $3,1 \%$ & $14,8 \%$ & $8 \%$ & $26,6 \%$ & $3,9 \%$ & $8,1 \%$ & $5,8 \%$ \\
\hline Silvicultura & $0,0 \%$ & $0,0 \%$ & $100,0 \%$ & $0,0 \%$ & $0,1 \%$ & $5,4 \%$ & $0,1 \%$ & $0,1 \%$ & $0,0 \%$ & $0,3 \%$ & $0,0 \%$ & $0,1 \%$ & $1,9 \%$ \\
\hline $\begin{array}{l}\text { Pequenos animais } \\
\text { (avicultura) }\end{array}$ & $2,0 \%$ & $30,1 \%$ & $0,0 \%$ & $1,9 \%$ & $16,2 \%$ & $7,6 \%$ & $7,4 \%$ & $6,3 \%$ & $3,7 \%$ & $10,5 \%$ & $5,6 \%$ & $6,8 \%$ & $7,1 \%$ \\
\hline Outros & $1,1 \%$ & $1,4 \%$ & $0,0 \%$ & $1,4 \%$ & $1,1 \%$ & $1,1 \%$ & $4,6 \%$ & $3,1 \%$ & $3,5 \%$ & $9,7 \%$ & $2,6 \%$ & $4,3 \%$ & $3,2 \%$ \\
\hline Total & $100 \%$ & $100 \%$ & $100 \%$ & $100 \%$ & $100 \%$ & $100 \%$ & $100 \%$ & $100 \%$ & $100 \%$ & $100 \%$ & $100 \%$ & $100 \%$ & $100 \%$ \\
\hline
\end{tabular}

Fonte: IBGE, Censo agropecuário de 1995-1996. Processamentos especiais do autor.

\subsubsection{Atuação institucional e "Combinações C de grupos de produtos"}

Reiteramos a noção de que as trajetórias se desenvolvem confrontando-se em concorrência materializada no embate entre as estruturas que operam os processos produtivos e suas instituiçōes de suporte. Os modos como o ambiente institucional age sobre as estruturas produtivas e é influenciado por elas são, assim, determinantes na concorrência entre as trajetórias, fundamento no diferencial de rendimentos que as qualificam nessa concorrência (Dosi, 2006; Arthur, 1994). 
Para tratar essa questão, as informações relativas ao crédito agropecuário no censo têm significado especial, pois expressam bem mais que recursos de empréstimo. É que, na agricultura, o crédito é fundamentalmente crédito de fomento e, como tal, mecanismo de política. De modo que, em torno dele, se movimentam outras políticas - suas instituições e organizações mediadoras -, sendo as mais notórias as de pesquisa tecnológica e as de assistência técnica. Ademais, o crédito reflete o estado geral do ambiente institucional nas áreas rurais. Pois, onde há políticas de ordenamento territorial, há crédito; onde as relações de propriedade da terra são dúbias, não há crédito; ou, se existe apesar disso, há algum tipo de organização que o garante. Desse modo, a variável crédito pode ser vista como proxy das relaçôes institucionais dos agentes e suas formas produção. Ademais, quando o censo agropecuário se realizou em 1995, a política de crédito baseada nos fundos constitucionais vigia havia sete anos, sendo o FNO a mais importante política rural em andamento na região (Costa, 2005, 2006).

Adotamos, por isso, um Índice de Densidade Institucional (IDI) a partir do crédito, o qual resulta da divisão entre participação percentual das "Combinações C de grupos de produtos" no crédito (\% que acessaram do crédito total) e a participação respectiva no VBP rural (\% do VBP rural). Na Tabela 5 estão os resultados desse procedimento considerando a ocorrência da "Combinação C" no espaço. Se o valor do IDI for maior que 1, significa que a Combinação $C$ acessou mais crédito que sua importância econômica, permitindo inferir que teve um ambiente institucional que a favoreceu na razão direta do valor do IDI.

Alguns resultados devem ser sublinhados:

1) Todas as combinações patronais apresentam IDI maior que 1 , devendo-se sublinhar os seguinte:

a) A patronal C2 se destaca com IDI = 2,67. Trata-se da combinação dominada por culturas permanentes, com rentabilidade contestada, objeto demonstrado de investimento, cuja fonte agora se explicita melhor.

b) Acima indicamos três combinações patronais que seriam provavelmente sucessivas - momentos distintos da evolução de um único trajeto -, duas delas, a Combinação patronal C4 e Combinação patronal C5 confluindo para a outra, a Combinação patronal C1. Pois bem, essas três combinações se destacam na sequência: a patronal C5 $\operatorname{com}$ IDI $=2,34$, 
TABELA 5

Índice de Densidade Institucional ${ }^{\star}$ das Combinações $C$ dos grupos de produtos por mesorregiões e estados

\begin{tabular}{|c|c|c|c|c|c|c|c|c|c|c|c|}
\hline \multirow{3}{*}{$\begin{array}{l}\text { Localização geográfica } \\
\text { Mesorregião }\end{array}$} & \multicolumn{11}{|c|}{ Combinações (fatores) por forma de produção } \\
\hline & \multicolumn{5}{|c|}{ Patronal } & \multicolumn{5}{|c|}{ Camponês } & \multirow{2}{*}{ Total } \\
\hline & $\mathrm{C} 1$ & $\mathrm{C} 2$ & C3 & $\mathrm{C} 4$ & C5 & $\mathrm{C} 1$ & $\mathrm{C} 2$ & $\mathrm{C} 3$ & $\mathrm{C} 4$ & $\mathrm{C} 5$ & \\
\hline Vale do Acre & & 0,00 & & 1,27 & 0,00 & 0,96 & & & 0,68 & 1,16 & 0,88 \\
\hline Vale do Juruá & & & & 4,11 & 1,32 & & & & 0,02 & 0,27 & 0,33 \\
\hline Norte do Amapá & & & & 0,67 & 0,00 & & & 0,07 & 0,26 & 0,00 & 0,35 \\
\hline Sul do Amapá & & 0,00 & 1,02 & 0,27 & 0,00 & & 0,04 & 0,05 & 0,03 & & 0,61 \\
\hline Centro amazonense & 0,40 & 1,00 & & 1,96 & 15,17 & 0,23 & 0,11 & 0,24 & 0,14 & 0,21 & 0,52 \\
\hline Norte amazonenense & & & & & 0,00 & & 0,00 & & 0,00 & 0,00 & 0,00 \\
\hline Sudoeste amazonenense & & & & 0,55 & 0,36 & 0,01 & 0,13 & & 0,15 & 0,44 & 0,22 \\
\hline Sul amazonense & & & & 0,00 & 1,03 & & 0,06 & 0,00 & 1,11 & 0,68 & 0,55 \\
\hline Baixo Amazonas & 3,38 & 2,44 & 0,00 & 0,52 & 0,39 & 0,50 & & 0,25 & 0,22 & 0,03 & 0,51 \\
\hline Marajó & 0,18 & & & & 0,31 & & 0,04 & 0,02 & 0,08 & & 0,06 \\
\hline Metropolitana de Belém & & 0,30 & & & - & 0,65 & 0,43 & & 0,26 & & 0,33 \\
\hline Nordeste paraense & 0,57 & 1,29 & & 0,03 & 11,73 & 0,39 & 0,57 & & 0,07 & 0,10 & 1,12 \\
\hline Sudeste paraemse & 0,89 & 18,44 & & 1,83 & 0,33 & 0,89 & 1,61 & 0,53 & 0,59 & 0,87 & 1,44 \\
\hline Sudoeste paraense & 1,87 & 0,78 & & 1,79 & 0,38 & 1,90 & & 0,38 & 0,34 & & 1,62 \\
\hline Leste rondoniense & 0,56 & 1,14 & & 0,81 & 0,73 & 0,61 & 0,05 & 0,47 & 0,16 & 0,84 & 0,64 \\
\hline Madeira-Guaporé & 1,58 & & & 0,57 & 3,65 & 6,44 & 0,77 & 0,95 & 0,26 & 1,86 & 3,21 \\
\hline Norte de Roraima & & 2,44 & & 1,44 & - & 0,63 & & 1,44 & 0,47 & 0,65 & 1,02 \\
\hline Sul de Roraima & & 0,16 & & 1,13 & 8,11 & 2,37 & & 1,51 & 0,57 & 6,19 & 2,26 \\
\hline Ocidental do Tocantins & 1,77 & & & 2,75 & 4,17 & & & & 0,22 & 1,30 & 1,76 \\
\hline Oriental do Tocantins & 2,63 & & & 1,92 & 2,30 & 2,01 & & & 0,68 & 0,71 & 1,59 \\
\hline Total & 1,39 & 2,67 & 0,83 & 1,75 & 2,34 & 0,83 & 0,43 & 0,23 & 0,30 & 0,67 & 1,00 \\
\hline
\end{tabular}

Fonte: IBGE, Censo agropecuário de 1995-1996. Processamentos especiais do autor.

* Participação relativa do crédito obtido dividido pela participação relativa do VBP. 
a patronal C4 com IDI $=1,75$ e a patronal C1 com IDI $=1,39$. Essa curiosa hierarquia no IDI é particularmente verdadeira nas duas mesorregiōes já mencionadas do Tocantins e na Madeira-Guaporé, em Rondônia. Mas ocorre também parcialmente no sudoeste e sudeste do Pará e em Roraima.

c) Por seu turno, a patronal C3, comandada por silvicultura - uma das duas patronais com atributos classe G1 -, apresenta IDI menor que 1.

2) Todas as combinações camponesas tem IDI menores que 1, com as seguintes diferenças a considerar:

a) A mais relevante é que a Combinação camponês $C 1$, em que se destacam as culturas permanentes e a pecuária leiteira, ambos os grupos de produto com atributo G1, apresenta o maior IDI $(0,83)$.

b) A segunda maior expressão do IDI foi o da Combinação camponês C5 $(0,67)$ : dominada por culturas temporárias e pecuária de corte.

c) O mais baixo IDI foi o da Combinação camponês C3 $(0,23)$, a qual se indicou acima como provavelmente preliminar a Combinação camponês C1.

d) Também são muito baixos os IDI da Combinação camponês C2 $(0,43)$ e da Combinação camponês C4 (0,30): as duas combinações ancoradas em produção extrativa não-madeireira.

\subsubsection{Evolução das "Combinações C dos grupos de produtos" por uma década}

As trajetórias evoluem em concorrência, cujo andamento se expressa na diferença nos ritmos de expansão que demonstram. As relaçóes dinâmicas entre relevância social, nível de compensação privada e capacidade de acumulação, por uma parte, e ambiente institucional e base produtiva, por outra; as interações, pois, que transformam externalidades em rendimentos crescentes privadamente apropriados - tanto maiores tais rendimentos em favor de um procedimento tecnológico, quanto mais dominante ele seja no conjunto -, referidas a cada trajetória, se expressam, como síntese, na sua capacidade de expansão.

Para analisar esse ponto avançando a ideia de que às "Combinaçóes $\mathrm{C}$ de grupos de produtos" subjazem trajetórias, obtiveram-se as taxas anuais de expansão de cada uma dessas combinações pelo seguinte procedimento: 
1) Calcularam-se as taxas anuais de crescimento dos grupos de produtos com base no produto real do agregado. Uma série de valores de produto real constitui indicador da flutuação das quantidades agregadas de produtos de natureza diferente, sendo cada ponto a soma do produto das quantidades no ponto (no ano) por um vetor de preço fixo para todos os pontos (em nosso caso a média dos preços de 1994 a 1996).

2) As taxas de crescimento dos grupos de produto relativas a um mesmo ano (ver Tabela 6) foram ponderadas pelas proporções com que os grupos respectivos participam na Combinação C (ver Tabela 4), resultando na sua taxa de crescimento agregado. Enunciando de outro modo, as taxas de incremento anual das composições Ci são os elementos do vetor coluna $T_{i}=\left(S_{i j}\right)$. $\left(r_{j}\right)$, onde os elementos da matriz $S_{\mathrm{ij}}$ são as participaçôes relativas dos grupos de produtos $j$ nas composições $\mathrm{Ci}$, e os do vetor coluna $\mathrm{r}_{\mathrm{j}}$ são as taxas de crescimento do grupo de produtos $j$. Os resultados estão nos Gráficos 1 e 2.

3) Calcularam-se as taxas de crescimento médio anual das "Combinações C" de modo a captar as flutuações no tempo. Assim, as taxas de crescimento anual $\bar{r}$ foram obtidas por regressão das séries contínuas, a partir da logaritimazação da fórmula $A_{t}=A_{0} \cdot(1+r)^{t}$, para $A_{t}$ os números-índices da evolução da "Combinação C" e $t$ a variável de tempo (os resultados estão entre parênteses na legenda dos Gráfico 1 e 2).

Ressaltam-se os seguintes resultados: a Combinação patronal C3 ( $\mathrm{r}=11 \%$ a.a.) e a Combinação patronal C2 $(r=11 \%$ a.a. $)$ destacaram-se em crescimento. A primeira corresponde à expectativa de que combinaçóes dominadas por grupos de produtos com classe de atributo G1 tenderiam a prevalecer pela consistência de seus fundamentos. A segunda corresponde à expectativa derivada da sua grande densidade institucional. Por sua vez, as três combinações que parecem sucessivas crescem, de formas semelhantes, contínuas, a taxas crescentes, obedecendo, contudo, a uma hierarquia que indica liderança da Combinação patronal C1 $(\mathrm{r}=8,7 \%$ a.a.), seguida da Combinação patronal C4 (8\% a.a.) e da Combinação patronal C5 $(6,6 \%$ a.a. $)$.

Correspondendo à expectativa, a Combinação camponês $\mathrm{C} 1$, com a maior densidade de grupos de produtos com atributo G1 e a maior densidade institucional entre os camponeses, apresenta um crescimento sustentado à maior taxa média de crescimento na forma de produção (10\% a.a.). As segunda e terceira taxas de 
TABELA 6

Números-índices da evolução do produto real dos grupos de produtos - Região Norte, 1995 a 2004 (1995 = 1)

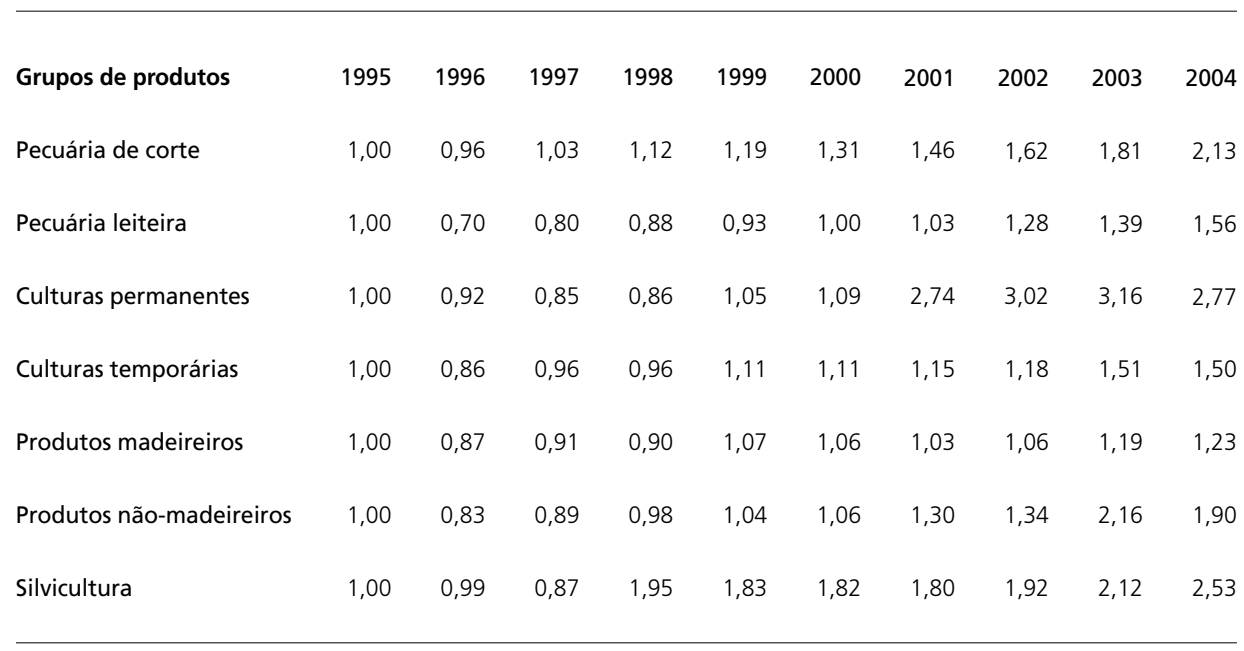

Fonte: IBGE, Estatísticas Agrícolas Municipais (PAM), Estatísticas Pecuárias Municipais (EPM), Produção Extrativa Vegetal, Pesquisa Pecuária Municipal.

Obs.: 1) Todos os estados da região Norte. 2) Produto real é o indicador do movimento de quantidades agregadas obtido pela multiplicação das quantidades de todos os anos por um vetor de preço fixo, em nosso caso a média dos preços de 1994 a 1996. Para culturas permanentes, culturas temporárias, produtos madeireiros e não-madeireiros e silvicultura, consideraram-se todos os produtos acompanhados pelo IBGE nos respectivos grupos. Para pecuária leiteira, considerou-se o número de vacas ordenhadas. Para pecuária de corte, considerou-se o rebanho total menos o número de vacas ordenhadas.

crescimento são as relativas à Combinação camponês C2 (9,2\% a.a.) e à Combinação camponês C4 (8,4\% a.a.), nas quais, lembre-se, o extrativismo não-madeireiro apresenta relevância. A menor de todas as taxas de crescimento é o da Combinação camponês C3 (6,9\% a.a.), a combinação que parece ser estágio anterior à Combinação camponês C1. A segunda menor taxa verificada foi a da Combinação camponês C5 (7,6\% a.a.), que compõe, com notável exclusividade, pecuária de corte e culturas permanentes.

\section{As trajetórias tecnológicas reveladas}

Qualificada a produção quanto à relevância social, à efetividade na compensação privada e ao desempenho no investimento; verificada, ademais, a estrutura das relações que seus componentes guardam entre si - o nível em que se constituem produçóes 
GRÁFICO 1

Evolução das Combinações $C$ dos grupos de produtos da forma de produção patronal - 1995-2004 (números-índices, $1995=100$ )

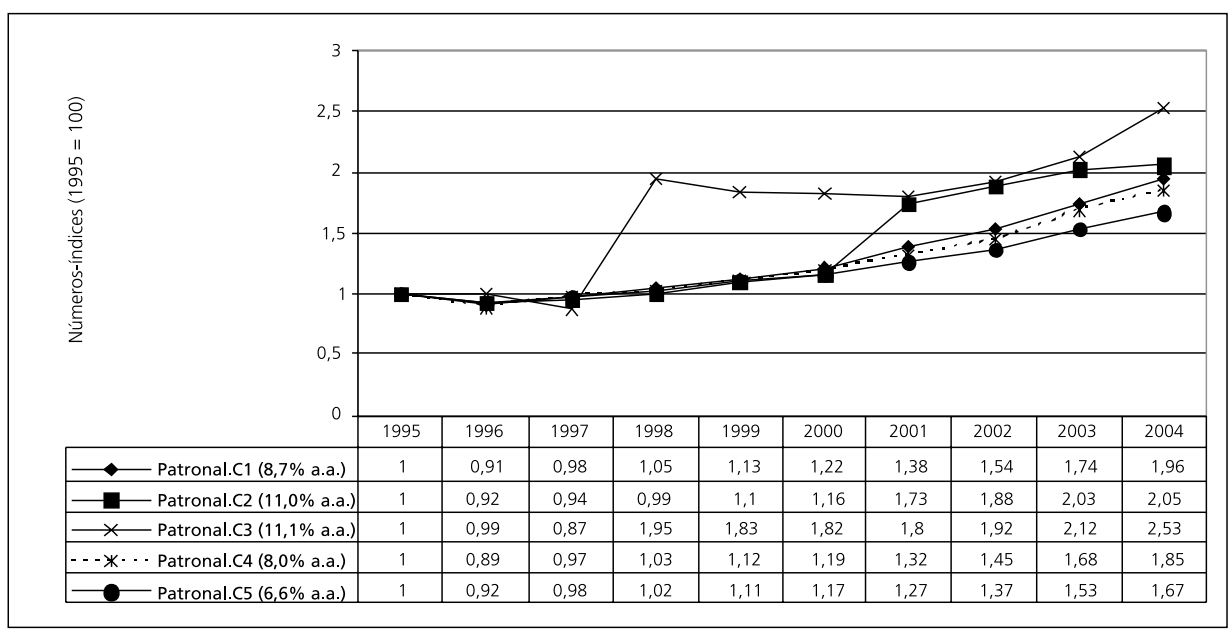

Fonte: Tabela 3 e Tabela 5. Ver esclarecimentos metodológicos no texto.

GRÁFICO 2

Evolução das Combinações $C$ dos grupos de produtos da forma de produção camponesa - 1995-2004 (números-índices, 1995 = 100)

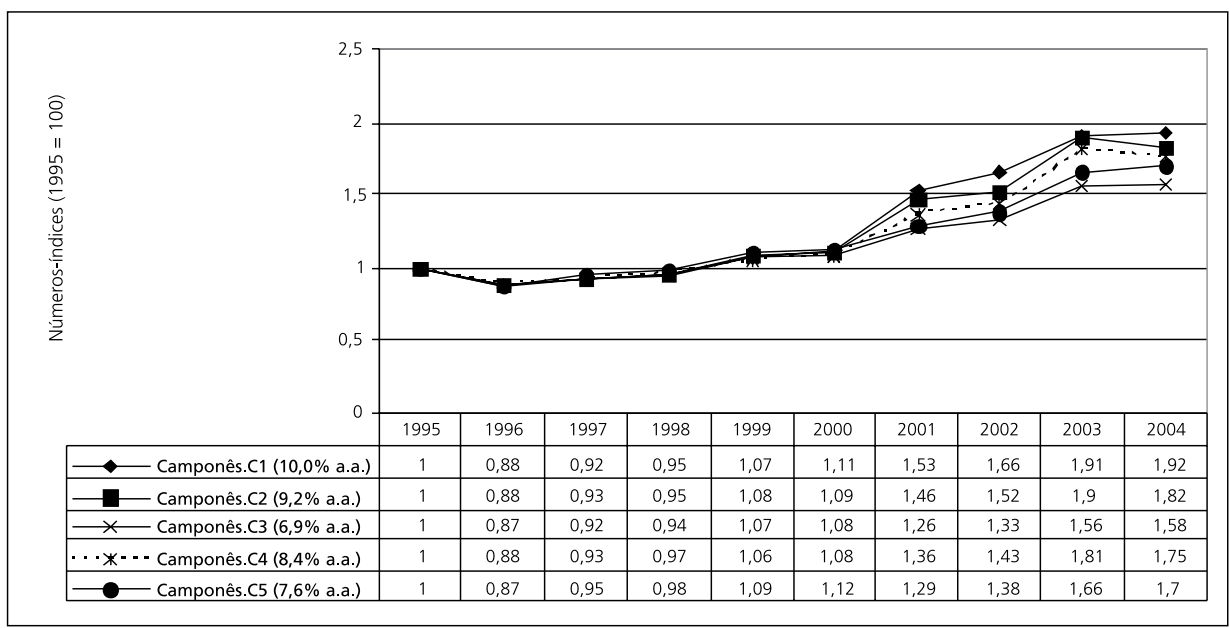

Fonte: Tabela 3 e Tabela 5. Ver esclarecimentos metodológicos no texto. 
interdependentes; visto, enfim, como essas combinações sofrem a interveniência das instituiçōes e como têm evoluído no período 1995-2004, permitimo-nos indicar os grandes movimentos que, resultantes de processos adaptativos conduzidos por agentes, de busca e seleção de possibilidades produtivas e reprodutivas, em que se incluem recursos institucionalmente distribuídos, conformam as trajetórias: a sequência de eventos estruturalmente coerentes que configuram o agrário da região Norte. Indicamos seis trajetórias, três patronais e três camponesas, cujas características (apresentadas na Tabela 7) passamos a discutir.

Importante esclarecer que no conjunto de dados criamos uma nova variável discreta chamada "Trajetórias reveladas", em que assinalamos com o atributo da trajetória correspondente (Trajetória patronal T4, por exemplo) todos os casos (ver Box 1) das "Combinações C" que compõem a trajetória em questão (no caso da Trajetória patronal T4, citada como exemplo, os casos que na variável "Combinaçôes C de grupos de produtos" estão assinalados com os atributos das Combinações patronal 1, patronal 4 e patronal 5). Em seguida cruzamos a nova variável "Trajetórias reveladas" com as variáveis indicativas das condiçōes econômicas e técnicas dos estabelecimentos, já disponíveis, e obtivemos as características das trajetórias apresentadas na Tabela 7 e comentadas abaixo:

1) Trajetória patronal $\mathrm{T} 4=$ patronal $[\mathrm{C} 5 \rightarrow \mathrm{C} 4 \rightarrow \mathrm{C} 1(\rightarrow \operatorname{Pec}$ Corte $\leftarrow) \rightarrow \mathrm{C} 5 \ldots]$.

A fórmula acima indica o que segue: há uma trajetória que chamamos de Trajetória patronal T4 liderada pela Combinação patronal C1, a qual se entendeu constituir ponto de chegada da Combinação patronal C4 e esta ponto de chegada da Combinação patronal C5. Na Combinação patronal C1, o grupo de produtos da pecuária de corte constitui o centro. E, dela, se originam os agentes que reestabelecem a Combinação patronal C5, fechando um ciclo que requer sempre novos espaços. Seguem as características da Trajetória patronal T4:

a) Em 1995 atuavam na Trajetória patronal T4 27.831 estabelecimentos (ver primeira linha da Tabela 7), os quais, controlando 33,3 milhões de hectares com 18,4 milhões deles transformados em pastagens, produziam, naquele ano, $28 \%$ do VBP do setor rural da região Norte.

b) Os procedimentos tecnológicos subjacentes são extensivos em terra, com uma produtividade por trabalhador de $\mathrm{R} \$ 9.673,40$ (valores do VBP corrigidos para 2005) e por área $\mathrm{R} \$ 52,48$ por hectare, para uma relação terra-trabalhador de 184,31 hectares por trabalhador. 
c) Como implicação dessa característica tecnológica, $71 \%$ das áreas degradadas por atividades agropecuárias na região foram geradas por essa trajetória $(1,6$ milhões de hectares em 1995): aproximadamente 1/10 da área por ela utilizada, pois, é descartado a cada ano, requerendo substituição. Por isso, a trajetória explica $73 \%$ dos investimentos declarados em terras na região, a partir de agentes já nela estabelecidos, que continuamente retornam da Combinação patronal $\mathrm{C} 1$ à posição inicial da Combinação patronal C5.

d) O Índice de Intensidade Institucional (IDI) de 1,63 é alto, demonstrando um correspondente poder da trajetória de configuração das políticas públicas em seu favor. O que explica, em parte, a elevada taxa de investimento de $36 \%$ da renda líquida (em que, além dos já mencionados investimentos em terras, se incluem $63 \%$ de todos os investimentos do setor na aquisição de animais e $55 \%$ das inversões em máquinas).

e) A evolução do VBP entre 1995 a 2004 se fez a uma taxa de 8,2\% a.a., atingindo ao final R\$1,3 bilhão. E tal evolução se fez, no que se refere à intensidade do uso do solo, dominantemente nas mesmas bases e procedimentos técnicos, por todo período. Como se demonstrou recentemente (Costa, 2006, 2007), à escala média de 500 cabeças, preponderante na região, quando se eleva a intensidade (o nível tecnológico) para sucessivamente 0,86 e 1,02 cabeça por hectare, a rentabilidade cai de $1,1 \%$ para $0,8 \%$ e, finalmente, para $-1,6 \%$. Paradoxalmente, para larga proporção dos estabelecimentos que conformam a trajetória, são economicamente eficientes quando tecnologicamente tradicionais e atrasados extensivos no uso do solo. Seja o conhecimento tácito portado pelos agentes econômicos dominantes, seja aquele desenvolvido institucionalmente nesse meio-tempo, parecem não ter sido capazes de alterar essa característica da trajetória. De modo que tal crescimento deverá ter correspondido a 3,2 milhōes de hectares de áreas degradadas em 2004.

f) Tal expansão se faz, por outra parte, tencionando ou superando todas as demais trajetórias, com exceção da Trajetória patronal T3. Observamos o fenômeno da concorrência entre as trajetórias nas unidades territoriais do seguinte modo: primeiro, encontramos o VBP de cada trajetória para cada microrregião, criando as variáveis VBP Trajetória (1...6); depois, encontramos as correlações de Pearson entre as variáveis "VBP Trajetória". Se a correlação entre duas trajetórias é positiva e alta, significa que elas se desenvolvem nos mesmos espaços de modo sinérgico - ou complementar. Se a correlação é alta e negativa, significa que elas se desenvolvem em concorrência, superando uma 
à outra. Se a correlação é próxima de zero, significa que são indiferentes. Os resultados estão na última parte da Tabela 7. Pois bem, verificamos o grau de tensão e nível de concorrência e superação no caso da Trajetória patronal T4: em relação à Trajetória patronal T1, a correlação de Pearson foi igual a -0,026; em relação à Trajetória patronal T2, -0,206; em relação à Trajetória patronal T5, -0,140, e, por último, em relação à Trajetória patronal T6, -0,104.

g) Nessa capacidade de concorrência que a trajetória demonstra e na força destrutiva dela derivada, encontram-se os desafios para a produção do conhecimento (C\&T) e toda institucionalidade para o desenvolvimento na região, situados num espectro que vai da criação (e desenvolvimento dos mecanismos de internalização) de possibilidades técnicas eficientes para o uso permanente dos recursos naturais no longo prazo (o que arrefeceria a força de curto prazo) até a formação de técnicas eficientes para corrigir os danos, internalizando à trajetória etapas de reutilização das áreas já degradadas.

2) Trajetória patronal T5 = patronal C2 $(\rightarrow$ Permanentes + Avicultura $\leftarrow)$.

Representa a Combinação patronal C2, baseada em cultura permanentes e avicultura:

a) A avicultura se realiza na região como momento de uma trajetória de maior abrangência, em relação à qual as especificidades regionais apresentam pouca interveniência - os problemas das plantas de produção não se distinguem muito dos de plantas industriais que aqui se instalam.

b) Quanto às culturas permanentes, há questôes particulares à sua implantação na região, que, criando problemas particulares a exigir soluções próprias, configuram trajetória autônoma. Na perspectiva patronal, a implantação de tipo de cultura tem assumido na Amazônia características de plantation - grande extensão de plantio homogêneo. O resultado é uma recorrente inconsistência em termos de lucratividade - que nossa análise aqui também detectou -, comprometendo a capacidade de expansão e afirmação da trajetória.

c) Em 1995 eram 4.444 estabelecimentos produzindo 4\% do VBP rural da região. Ocupando 29,2 mil trabalhadores equivalentes, dispunha de uma área total de 2,1 milhões de hectares, dos quais utilizava 755 mil deles.

d) Com produtividade monetária por trabalhador, equivalente à trajetória anteriormente discutida, apresenta uma rentabilidade por área 2,5 vezes maior e, 
com 71,9 hectares por trabalhador, a menor relação terra-trabalho de todas as trajetórias patronais. Um resultado disso é que se associam a ela 36 mil hectares de áreas degradadas, um valor relativamente baixo.

e) A trajetória vem apresentando taxa de crescimento de $11 \%$ a.a., ao par do maior Índice de Densidade Institucional (IDI) no setor rural da região. Ademais, tem apresentado um crescimento claramente compatível com a Trajetória patronal T1 (correlação de Pearson de 0,133), Trajetória patronal T2 $(0,270)$, sendo relativamente indiferente em relação à Trajetória patronal T5 $(0,092)$.

f) De modo que sua inconsistência em termos de rentabilidade, podendo-se constituir em barreira para sua evolução - uma alternativa bem mais defensável do ponto da sustentabilidade ecológica que a Trajetória patronal T4 antes discutida -, se coloca como um desafia à C\&T e toda a institucionalidade para o desenvolvimento. Trata-se de superar problemas gerais do paradigma da agricultura homogênea e de grande escala na Amazônia. A agricultura em geral, mas sobretudo a agricultura de grande escala tem evoluído na região sob o peso de dificuldades de ordem técnica: são os transtornos que sofrem os sistemas agronômicos intensivos, de composição botânica homogênea, como resultado da fortíssima pressão da biodiversidade amazônica, que, favorecida pelo clima quente e úmido, se manifesta ou em um sem-número de fungos e bactérias que elevam a probabilidade de predação das variedades agrícolas, ou em um sem-número de plantas invasoras cuja concorrência limita o desenvolvimento dessas variedades. Ademais, a elevada pluviometria acelera a lixiviação do solo tanto em relação aos nutrientes naturais quanto aos insumos químicos provindos da indústria. Tais determinantes reduzem os ciclos de vida das culturas, a vida útil dos elementos de capital físico e a resiliência produtiva do capital natural, encarecendo relativamente ou, mesmo, impossibilitando certos sistemas produtivos na razão direta da sua frequência e extensão. A exigente tarefa de contrariar tais tendências constituiria a agenda da C\&T para essa trajetória.

3) A patronal T6 = patronal C3 $(\rightarrow$ Silvicultura $\leftarrow)$.

Representa a Combinação patronal C3, especializada em silvicultura:

a) São apenas três os estabelecimentos que em 1995 atuavam nessa alternativa tecnológica, produzindo $2 \%$ do VBP rural da região, ocupando 2,4 mil pessoas numa área de 1,2 milhões de hectares, dos quais 137,4 plantadas. 
b) A produtividade monetária por trabalhador é mais que cinco vezes a das demais trajetórias patronais e por área é relativamente baixa, de modo que a relação terra-trabalho é a maior de todas. A participação no estoque de áreas degradadas é, por sua vez, zero.

c) A taxa de crescimento tem sido também de $11 \%$ a.a. Diferentemente das plantations da culturas permanentes, as da silvicultura são consistentes, apresentando, como já se viu mais de uma vez, classe de atributos G1.

d) O principal desafio para a institucionalidade para o desenvolvimento, em que se inclui a produção de conhecimento (C\&T), é o de conectar essa trajetória com a Trajetória patronal T1, acima discutida, tornando-a uma sucessão factível e de baixo risco. Desafio relevante, considerando que se trata da trajetória de mais baixo Índice de Densidade Institucional de todas protagonizadas por estruturas da produção patronal.

4) Trajetória camponês $\mathrm{T} 1=$ camponês $[\mathrm{C} 3 \rightarrow \mathrm{C} 1(\rightarrow$ CultPerm+Leite $\rightarrow)]$.

Liderada pela Combinação camponês $\mathrm{C}$ 1, a qual se constitui ponto de chegada da Combinação camponês C3. Na Combinação camponês $\mathrm{C} 1$, para a qual converge a Combinação camponês $\mathrm{C} 3$, funciona como atrator (centro de convergência) das culturas permanentes e da pecuária de leite, ambas as atividades com a consistência que a classe de atributo G1 permite derivar:

a) Baseada nesses fundamentos, com uma taxa de investimento de $7 \%$ da renda líquida em 1995, a trajetória logrou se expandir a $11 \%$ a.a. até 2004, passando sua participação relativa no VBP rural da região de $29 \%$ para $31 \%$.

b) Em processos produtivos organizados por 171.292 estabelecimentos, a trajetória absorveu próximo de $50 \%$ de todos os investimentos feitos em culturas permanentes na região - confirmando sua característica de fixidez espacial, a trajetória deságua em espaços dados - e $18 \%$ da aquisição de animais.

c) Por outro lado, controlando 9,3 milhões de hectares dos quais utiliza pouco mais que $1 / 3$, os estabelecimentos que protagonizam essa trajetória mobilizam uma força de trabalho de 723 mil trabalhadores equivalentes: uma produtividade monetária de $\mathrm{R} \$ 2.509,45$ por trabalhador, produtividade por área de $\mathrm{R} \$ 104,48$ por hectare e uma relação terra-trabalho de 12,9 hectares.

d) A trajetória explica 10\% das áreas degradadas acumuladas em 1995: 228 mil hectares. Uma característica fundamental da trajetória é a de que produz uma 
intensificação dos processos produtivos por especialização parcial dos sistemas, que, todavia, mantêm um alto grau de complexidade. Isso é importante numa perspectiva de sustentabilidade e constitui desafio de grande envergadura para as instituiçôes voltadas ao desenvolvimento: para as instituições de C\&T, que sejam capazes de produzir conhecimentos ajustados às necessidades tecnológicas de sistemas agronômicos complexos, fora dos padrões das simplificaçôes da agricultura altamente especializadas, e para as organizações de fomento, as quais têm que ajustar seus mecanismos de política a uma clientela difusa e heterogênea, em lugar do tipo de clientela com a qual tem mantido relações preferenciais. Sublinhe-se que tais conhecimentos são fundamentais para elevar a capacidade de concorrência da trajetória, que se mostrou notavelmente contestável na relação com a Trajetória camponês T3 (a trajetória camponesa extensiva), em relação à qual a correlação de Pearson foi de $-0,231$; mostrou-se também vulnerável, embora fracamente, à Trajetória camponês T4 (correlação de -0,026).

e) Ademais, há desafios institucionais também importantes em dois tipos de ajustamentos que se produzem como parte da trajetória: a montante, ajustamentos para tornar mais eficiente a passagem dos estabelecimentos que atuam pela Combinação camponês C3 à Combinação camponês $\mathrm{C} 1$; e, a jusante, no ajustamento das relações crescentes que se estabelecem com a indústria e com mercados amplos, nacionais e internacionais.

5) Trajetória camponês $T 2=$ camponês

$[\mathrm{C} 4 \rightarrow \mathrm{C} 2(\rightarrow$ ExtratNãoMad + Agri + Silv. $\leftarrow)]$.

Liderada pela Combinação camponês C2, ponto de chegada da Combinação camponês $\mathrm{C} 4$, essa trajetória se faz tendo como base o extrativismo não-madeireiro em combinação com agricultura diversa, cujos resultados são sistemas agroflorestais. Seria expressão de um paradigma - no qual os processos produtivos pressupõe, em algum nível, a preservação da natureza originária:

a) Seguem essa trajetória 130.593 estabelecimentos camponeses na região Norte, que controlam 3 milhões de hectares - dos quais apenas $1 / 5$ aplicados em uso agropecuário - e ocupam 502 mil pessoas.

b) A produtividade monetária por trabalhador é a menor de todas as trajetórias protagonizadas por camponeses, mas a produtividade por área é a maior de todas posto que a relação terra-trabalho é de apenas 5,99 hectares por trabalhador. 
c) Produzindo $18 \%$ do VBP do setor rural da região Norte, explica meros 3\% da área degradada; tendo seus principais grupos de produtos atributo G2 (consistência na rentabilidade privada e relevância social, sem constituir lócus ou fundamento de investimento), apresenta uma taxa de crescimento de $9 \%$ a.a. entre 1995 e 2004, não obstante sua taxa de investimento em 1995 ser de meros 3\%.

d) Não obstante, seus investimentos explicam 39\% de todos os investimentos em silvicultura e $16 \%$ em culturas permanentes na região. Essa trajetória seria objeto óbvio de uma atuação revolucionária da C\&T e se prevalece uma abordagem de desenvolvimento da região como fronteira do capital natural.

e) O Índice de Densidade Institucional é o menor de todas as trajetórias: 0,38. Todavia, crescem as necessidades, a partir de um conjunto de indústrias (polpa de frutas, cosmética etc.) que tendem a aumentar em significado.

f) As instituições de C\&T tenderão correspondentemente a receber demandas provindas daí e as possibilidades de cooperação podem crescer nessa interface. Resolver, todavia, os problemas tecnológicos da trajetória da produção rural a partir da perspectiva da indústria pode ampliar a assimetria na relação agriculturaindústria e repartir de modo desigual os resultados, o que deverá ser antecipado e monitorado por pesquisas patrocinadas pelas ciências da sociedade.

g) A trajetória apresenta o enorme desafio de exigir um conhecimento ecológico orientado à produção complexa, a agroecologia - ramo ainda pouco representativo na formação do profissional de C\&T em geral e da P\&D agropecuária em particular. O progresso nessa área é imprescindível para aumentar a capacidade de concorrência da trajetória, hoje fortemente contestada na concorrência com as trajetórias Trajetória camponesa T3 (correlação de Pearson de -0,209) e Trajetória camponesa T4 $(-0,206)$.

6) A Trajetória camponês T3 = camponês $[\mathrm{C} 5(\rightarrow$ PecCorte $\leftarrow) \rightarrow$ C5 $\ldots .$.$] .$

Representa a Combinação camponês C5, combinação organizada por estabelecimentos camponeses na qual a pecuária de corte desempenha papel fundamental:

a) A trajetória representava 18\% do VBP em 1995, perdendo um ponto percentual de expressão ao longo dos dez anos seguintes.

b) Protagonizada por 109 mil estabelecimentos que detinham quase 7 milhões de hectares; suas relações técnicas são as mais extensivas no que tange à terra e 
TABELA 7

Características das trajetórias tecnológicas prevalecentes no setor rural da região Norte

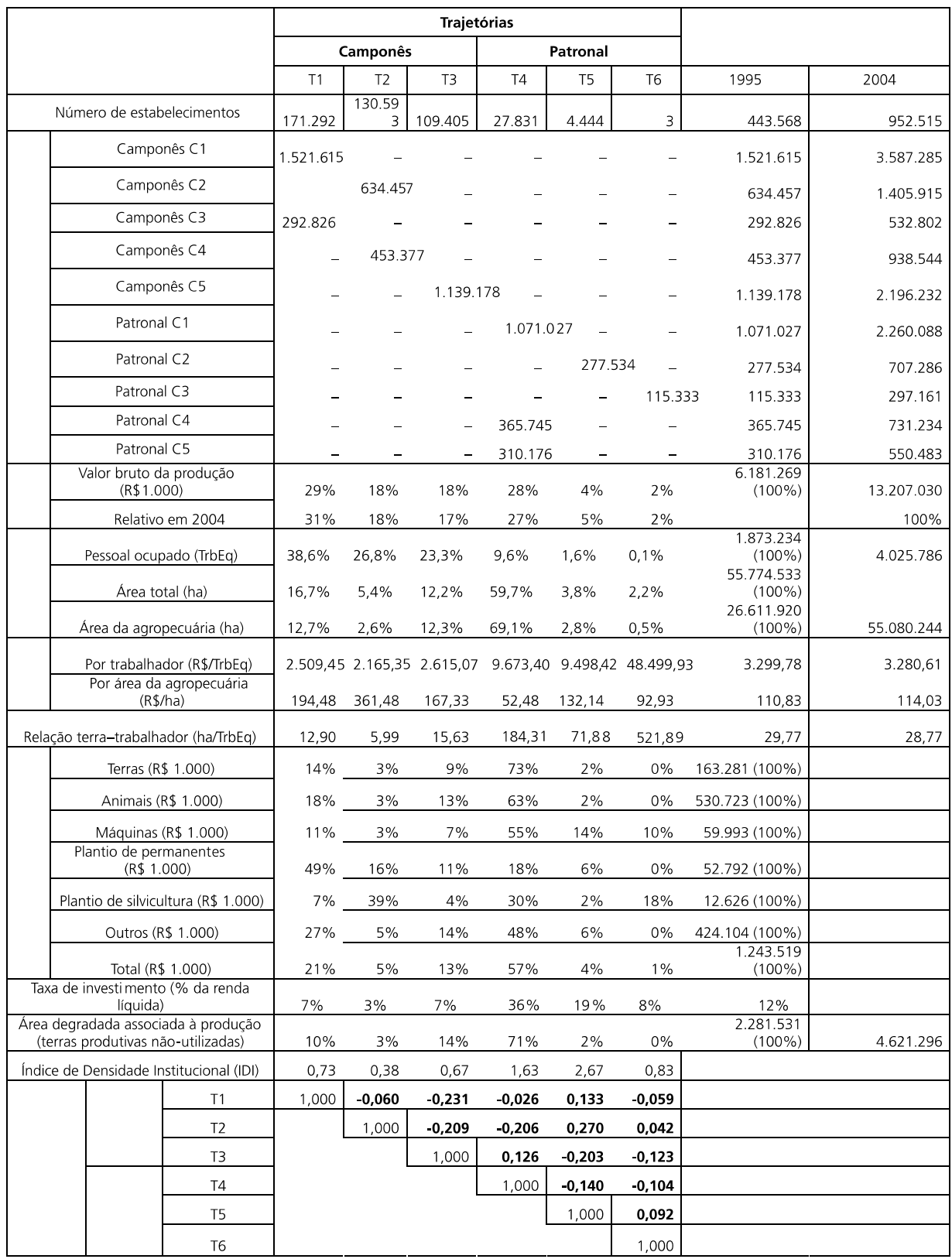

Fonte: IBGE, Censo agropecuário de 1995-1996; levantamentos anuais de produção agrícola. Processamentos especiais do autor. 
menos rentáveis no que tange ao trabalho de todas as trajetórias camponesas: rendimento por trabalhador de $\mathrm{R} \$ 2.615,07$, por unidade de área de $\mathrm{R} \$ 167,33$ e relação terra-trabalho de 15,6 hectares por trabalhador.

c) Por seu turno, explicava I $2 \%$ do estoque da áreas degradadas.

d) Os desafios dessa trajetória para a C\&T e a institucionalidade para o desenvolvimento são similares aos da Trajetória patronal T4 - resguardadas as características e necessidades dos estabelecimentos camponeses que protagonizam.

\section{Conclusões: sobre trajetórias, paradigmas e desenvolvimento sustentável}

Domina o universo rural do desenvolvimento capitalista um paradigma ou padrão tecnológico que se afirma pela eficiência demonstrada no controle tenso da natureza para que corresponda às necessidades industrialistas. As soluçōes se sucedem compondo trajetórias tecnológicas que se afirmam umas por maximizarem ganhos baseados no uso extensivo da terra e dos recursos naturais, ali onde a relação de propriedade fundiária o permite; outras, por maximizarem ganhos baseados no uso intensivo da terra e dos recursos naturais, lá onde os constrangimentos fundiários a isso levam. No primeiro caso, prevalecem as soluções mecânicas; no segundo, as químicas e, mais recentemente, as bioquímicas.

$\mathrm{Na}$ Amazônia esse paradigma "global" está presente tanto na esfera da produção de bens, controlada pelos agentes produtivos mediante seus critérios próprios de decisão, quanto no universo da gestão das políticas públicas, em que se destacam aquelas que condicionam a produção e difusão de conhecimento científico e tecnológico. Mas tal "paradigma agropecuário" se manifesta aqui por trajetórias particulares, marcadas por forte diversidade dos agentes, no que tange à razão decisória e às características estruturais, e por diversidade de situaçōes, no que se refere aos fundamentos naturais e fundiários de suas existências. Por outra parte, a história social de muitos desses grupos sociais organizou trajetórias outras que não são "agropecuárias", posto que pressupõem, em nível relevante, a manutenção da natureza originária. Nesse sentido, elas configuram um padrão tecnológico que poderíamos designar "paradigma extrativista" - porquanto perspectiva particular do uso social dos recursos e de resolução dos problemas a isso afetos.

Com efeito, localizamos e caracterizamos, com as estatísticas disponíveis, elementos de estruturação e dinâmica das grandes trajetórias que realizam tais padrões: 
1) No contexto de um paradigma agropecuário, em que as soluções tecnológicas supõem transformação profunda da natureza originária (agropecuária) se distinguiram:

a) Trajetória (patronal T4) conduzida por agentes patronais, marcada por uso extensivo do solo, homogeneização da paisagem (alto impacto na biodiversidade) e formação intensa de dejetos: na forma de emissões poluentes (pela queima da floresta na formação de plantações e pastagens) e na forma de áreas degradadas.

b) Trajetória (patronal T6) conduzida por agentes patronais, marcada por uso extensivo do solo, com homogeneização da paisagem (alto impacto na biodiversidade) e baixa formação de dejetos/impacto poluidor.

c) Trajetória (patronal T5) conduzida por agentes patronais, marcada por uso intensivo do solo, com homogeneização da paisagem (alto impacto na biodiversidade) e baixa formação de dejetos/impacto poluidor.

d) Trajetória (camponês T3) conduzida por agentes camponeses, marcada por uso extensivo do solo, homogeneização da paisagem (alto impacto na biodiversidade) e formação intensa de dejetos: na forma de emissões poluentes (pela queima da floresta na formação de plantações e pastagens) e na forma de áreas degradadas.

e) Trajetória (patronal T1) conduzida por agentes camponeses, marcada por uso intensivo do solo, com sistemas diversificados (baixo impacto na biodiversidade) e baixa formação de dejetos/impacto poluidor.

2) No contexto de um paradigma extrativista, no qual as soluções tecnológicas supõem integridade da natureza originária, distinguimos:

a) Trajetória (camponês T2) conduzida por agentes camponeses, marcada por uso altamente diverso das disponibilidades naturais, com baixíssimo impacto na biodiversidade e baixíssima formação de dejetos/impacto poluidor.

Há um embate entre as trajetórias, expressão do nível de oposição dos paradigmas que as abrigam. Entre os camponeses, a trajetória "extrativa" ou "agroflorestal" a Trajetória camponês T2 - se retrai com a expansão das trajetórias "agropecuárias", mais fortemente quando se trata da Trajetória campnês T3 e fracamente quando se trata do Trajetória camponês T1. Ela se retrai, igualmente, quando se expande a Trajetória patronal T4. 
Por sua vez, a trajetória "agropecuária" camponesa intensiva e diversa - Trajetória camponês $\mathrm{T} 1$ - se retrai quando expande a camponesa (Trajetória camponês T3, correlação -0,231) ou a patronal (Trajetória camponês T4, correlação -0,026) extensivas e predatórias.

Estabelecido que os desfechos desses confrontos dependem das eficiências relativas das trajetórias em atender necessidades sociais imbricadas na divisão social do trabalho de que, mediadas pelos mercados, fazem parte e das necessidades privadas expressas em compensações que garantem a reprodução social ascendente dos que as operam, opções estratégicas que favoreçam um desenvolvimento com maior esperança de sustentabilidade (social e ambiental) exigiriam esforços institucionais objetivos para tornar mais consistentes os fundamentos principalmente da Trajetória camponesa T1 e da Trajetória camponesa T2, mas também da Trajetória patronal T5 e da Trajetória patronal T6, de modo a habilitá-las na concorrência com a Trajetória camponesa T3 e a Trajetória patronal T4. Na validação desse princípio estratégico, residiria uma revolução institucional capaz de arregimentar os saberes tácitos e laboratoriais necessários a uma fronteira do capital natural e humano por suposto. Reviravolta nada fácil, posto que representaria inverter as disposições reinantes como indicado - subverter a ordem de grandeza dos Índices de Densidade Institucional que demonstramos.

Um último ponto deve ser lembrado. A análise conduzida, por se basear em pesquisa estrutural de dez anos atrás e proceder atualizações com os indexadores oficiais até 2004, não trata de fenômenos recentes de grande interesse, como a projeção sobre a Amazônia de duas trajetórias exogenamente estabelecidas e as iniciativas institucionais que vêm criando alternativas a serem consideradas. No primeiro caso, refiro-me à expansão, sobre áreas da região, do pacote para soja da trajetória mecânicoquímica vigente em plano mundial, tal como se adaptou a outras áreas do Brasil, e às técnicas de exploração florestal manejada, para o que se vem estabelecendo os arranjos institucionais necessários, nos quais se destaca o grande esforço no sentido do manejo de biomassa para uma combinação de produtos extrativistas (madeira, não-madeireira e resíduos energéticos), numa ótica bioenergética que começa a receber maior atenção para uma política de desenvolvimento tecnológico. Trata-se do estabelecimento de novos marcos para os dois paradigmas acima tratados: um aprofunda a transformação dos fundamentos naturais na agricultura reduzindo-os, em níveis sem precedentes na região, a relações edafoclimáticas intensivamente manejáveis; o outro se apresenta como oportunidade de transformar a exploração madeireira na região de extrativismo de aniquilamento para extrativismo de coleta 
(não muito diferente, em seus efeitos quanto a sustentabilidade, do extrativismo não-madeireiro definidor da Trajetória camponesa T2). O significado disso para o futuro da região e suas expectativas de desenvolvimento moderno, porque economicamente consistente, socialmente equilibrado e ecologicamente sustentável, pode ser muito grande, exigindo, para seu adequado tratamento, novas pesquisas.

\section{Referências bibliográficas}

Arthur, W.B. Increasing returns and path dependence in the economy, Michigan: The University of Michigan Press, 1994.

Backhaus, K.; Erichson, B.; Plinke, W.; Weiber, R. Multivariate Analysemethoden, Berlim: Springer, 2000.

Becker, B. Síntese da produção científica em ciências humanas na Amazônia: 1990-2002, Brasília, CGEE, 2004 (mimeo).

Becker, B. "Geopolítica da Amazônia”, Estudos Avançados, São Paulo: IEA-USP, 19(53), p.71-86, 2005a.

"Dinâmica urbana na Amazônia", in Diniz, C.C.; Lemos, M.B., Economia e território, Belo Horizonte: EUFMG, p.401-428, 2005 b.

. "Síntese da produção científica em ciências humanas na Amazônia: 1990-

2002”, in Becker, B.; Alves, D.; Costa, W., Dimensōes humanas da biosfera-atmosfera na Amazônia, São Paulo: EDUSP, p.13-38, 2007.

Boyer, R. "Formalizing growth regimes", in Dosi, G.; Freeman, C.; Nelson, R.; Silverberg, G.; Soete, L. (eds.), Technical change and economic theory, Londres, Nova York: Printer Publisher, p.608-635, 1988.

Bühl, A.; Zöfel, P. SPSS für Windows, Version 6.1: Praxisorientierter Einführung in die moderne Datenanalyse, Bonn: Addison, Wesley, Longman, 1996.

Castro, A.C. "Construindo pontes: inovações, organizaçōes e estratégias como abordagens complementares”, Revista Brasileira de Inovação, v.3, n.2, jul.-dez., 2004. 
CGEE-MCT/Embrapa/CONSEPA. Pesquisa sobre o papel das instituições estaduais de pesquisa agropecuária integrantes do Sistema Nacional de Pesquisa Agropecuária (Termo de Referência), Brasília, maio, 2006.

Costa, F. de A. Ecologismo e questão agrária na Amazônia, Belém: NAEA, Editora da UFPa, 1992.

"O investimento camponês: considerações teóricas", Revista de Economia Política, v.15, n.1, p.83-100, 1995.

"O uso dos recursos naturais na Amazônia: anotações para uma agenda das ciências da sociedade", in Moura, H.A. de (org.), A pesquisa social na Amazônia: avanços, lacunas e prioridades, Recife: FUNDAJ, Massangana, p.152-162, 1996.

Ciência, tecnologia e sociedade na Amazônia, Belém: CEJUP, 1998.

"Políticas públicas e dinâmica agrária na Amazônia: dos incentivos fiscais ao FNO”, in Tura, L.; Costa, F.A., Campesinato e Estado na Amazônia, Brasília: Brasília Jurídica, FASE, 2000a.

Formação agropecuária da Amazônia: os desafios do desenvolvimento sustentável, Belém: NAEA, $2000 \mathrm{~b}$.

"As ciências, o uso dos recursos naturais na Amazônia e a noção de desenvolvimento sustentável: por uma interdisciplinaridade ampla”, in Vieira, I; Silva, J.M.C.; Oren, D.C.; D’Incao, M.A., Diversidade biológica e natural da Amazônia, Belém: MPEG, 2001.

"Questão agrária e macropolíticas para a Amazônia", Estudos Avançados, São Paulo: IEA-USP, 19(53), 2005.

A pesquisa agropecuária na Amazônia e os fundamentos do desenvolvimento rural, Belém: NAEA, 2006a (relatório de consultoria para o Centro de Gestão e Estudos Estratégicos - CGEE, Brasília).

"Arranjos e sistemas produtivos e inovativos locais - As possibilidades do conceito na constituição de um sistema de planejamento para a Amazônia", Revista Brasileira de Inovaçôes, v.5, n.1, p.77-98, jan.-jun., 2006b.

"Capoeiras, inovações e tecnologias rurais concorrentes na Amazônia”, in Costa, F. de A.; Hurtienne, T.P.; Kahwage, C., Inovação e difusão tecnológica para sustentabilidade da agricultura familiar na Amazônia, Belém: NAEA, p.21-60, 2006c.

"Questão agrária na Amazônia e os sesafios estratégicos de um novo desenvolvimento", in Becker, B.; Alves, D.; Costa, W., Dimensöes humanas da biosfera-atmosfera na Amazônia, São Paulo: EDUSP, 2007a. 
Costa, F. de A. "A relação dos preços na agricultura dos Estados Unidos: uma observação baseada em eficiência reprodutiva”, Economia,v.8, n.1 p.139-159, jan.-abr., 2007b.

"A dinâmica peculiar dos investimentos agrícolas nos Estados Unidos (19481994): uma explicação baseada em eficiência reprodutiva”, Economia, v.8, n.2, p.289320, maio-ago., 2007c.

Dosi, G. "Technological paradigms and technological trajectories", Revista Brasileira de Inovaçōes, v.5, n.1, p.17-32, jan.-jun., 2006.

Egler, P. Organização e formas cooperativas da ciência e tecnologia na Amazônia, Brasília, CGEE, 2006 (mimeo.).

Fajnzylber, F. "Competitividad internacional en la América Latina”, Revista de la CEPAL, n.36, dez., 1988.

Goodman, D.; Sorj, B.; Wilkinson, J. Da lavoura às biotecnologias, Rio de Janeiro: Campus, 1988.

Hair, J.F.; Anderson, R.E.; Tatham, R.L.; Black, W.C. Multivariate data analysis, Nova Jersey: Prentice Hall, 1998.

Hayami, Y.; Ruttan, V.W. Agricultural development: an international perspective, Baltimore, Londres: Johns Hopkins University Press, 1980.

IBGE. Produção agrícola municipal - Brasil e estado do Pará, diversos anos.

Keynes, J.M. Teoria geral do emprego do juro e do dinheiro, Rio de Janeiro: Fundo de Cultura, 1970.

Martins, P.S. "Dinâmica evolutiva em roças de caboclos amazônicos”, Estudos Avançados, São Paulo: IEA-USP, 19(53), 2005.

Morel, R.L.M. Ciência e Estado: a politica cientifica no Brasil, São Paulo: T.A. Queiroz, 1979.

Nelson, R.R.; Winter, S.G. An evolutionary theory of economic change, Cambridge, Londres: Harvard University Press, 1982.

Possas, M.L. "Racionalidade e regularidades: rumo a uma integração micro-macroeconômica", Economia e Sociedade, n.2, ago., 1993.

. "Demanda efetiva, investimento e dinâmica: atualidade de Kalecki para a teoria macroeconômica”, Revista de Economia Contemporânea, v.3, n.2, jul.-dez., 1999. 
Possas, M.L.; Koblitz, A.; Licha, A.L.; Oreiro, J.L.; Dweck, E. "Um modelo evolucionário setorial”, Textos para Discussão, Porto Alegre, Programa de Pós-Graduação em Economia, n.1, 2001.

Prado, E. "Conceitos de ação racional e os limites do enfoque econômico", Revista de Economia Política, v.13, n.1, jan.-mar., 2003.

Romeiro, A.R. Meio ambiente e dinâmica de inovação na agricultura, São Paulo: FAPESP, ANNABLUME, 1998.

Sá, T.D.A. "Subsídios a uma agenda de pesquisa agropecuária e florestal para a Amazônia”, paper apresentado no Fórum Regional para Fortalecimento da Pesquisa Agropecuária na Região Amazônica, Belém, 8/11/2006, Brasília, Embrapa, 2006.

Sales Filho, S.L.M.; Silveira, J.M.F.J. "A teoria da inovação induzida e os modelos 'demand pull': uma crítica com base no enfoque neo-shumpeteriano", Anais do XXVIII Congresso Brasileiro de Economia e Sociologia Rural da SOBER, Florionópolis, 22-27 jul., 1990.

Simon, H. Reason in human affairs, Stanford: Stanford University Press, 1983.

Veiga, J.E. O desenvolvimento agrícola: uma visão histórica, São Paulo: EDUSP, HUCITEC, 1991.

Metamorfoses da política agrícola dos Estados Unidos, São Paulo: FAPESP, ANABLUME, 1994.

Vieira, I. "Aproveitamento da biodiversidade com ênfase para oportunidades de uso a partir do conhecimento autóctone", paper apresentado no Fórum Regional para Fortalecimento da Pesquisa Agropecuária na Região Amazônica, Belém, 8/11/2006.

Williamson, Oliver. The economic institutions of capitalism, Nova York: Free Press, 1985.

ENDEREÇO PARA CORRESPONDENCIA:

Francisco de Assis Costa - francisco_de_assis_costa@yahoo.com.br

Travessa Pirajá, 2.060

66083-165 - Belém (PA)

Fone: (91) 3276-8719 